Stephen M. Horan, CFA

D. Bruce Johnsen

\title{
The Welfare Effects of Soft Dollar Brokerage: Law and Economics
}

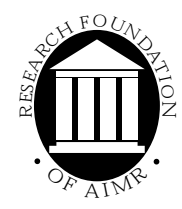

The Research Foundation of the Association for Investment Management and Research 


\section{The Research Foundation of the Association for Investment Management and Research \\ Board of Trustees \\ 1999-2000}

Chair

Deborah H. Miller, CFA

Massachusetts Financial Services

Vice Chair

H. Gifford Fong

Gifford Fong Associates

Executive Director

Katrina F. Sherrerd, CFA

AIMR

Thomas A. Bowman, CFA

AIMR

Gary P. Brinson, CFA*

Brinson Partners, Inc.

James L. Farrell, Jr., CFA

Farrell-SL Investment Management, Inc.

Khalid Ghayur, CFA

HSBC Asset Management Ltd.

Robert H. Jeffrey

Jeffrey Company
Martin L. Leibowitz

TIAA-CREF

Joan A. Payden, CFA

Payden \& Rygel

Frank K. Reilly, CFA

University of Notre Dame

Fred H. Speece, Jr., CFA

Speece Thorson Capital Group Inc.

Walter P. Stern, CFA*

Capital Group International, Inc.

R. Charles Tschampion, CFA

General Motors Investment

Management Corporation

James R. Vertin, CFA*

Alpine Counselors

Brian F. Wruble, CFA

Odyssey Investment Partners LLC

\section{Officers and Directors}

Executive Director

Katrina F. Sherrerd, CFA

AIMR

Research Director

Mark P. Kritzman, CFA

Windham Capital Management
Secretary

John H. Kitzmann AIMR

Treasurer

Timothy G. McLaughlin AIMR

\section{Research Review Board}

Stephen J. Brown

New York University

Joseph Cherian

Boston University

Roger G. Clarke

Analytic Investors, Inc.

Sanjiv Das

Harvard University

Bernard Dumas

INSEAD

Stephen Figlewski

New York University

Gary L. Gastineau John Nuveen \& Company

Stephen J. Gorman, CFA

Putnam Investments

Hélène Harasty, CFA

Lombard Odier \& Cie

Joanne M. Hill

Goldman, Sachs \& Company

David L. Ikenberry

Rice University

Takao Kobayashi

University of Tokyo

Robert W. Kopprasch, CFA

Smith Barney Capital Management

Emeritus
Andrew W. Lo

Massachusetts Institute of Technology

Alan Marcus Boston College

John J. Nagorniak, CFA Franklin Portfolio Associates

Paul O'Connell FDO Partners

Krishna Ramaswamy University of Pennsylvania

Gita R. Rao Wellington Management Company LLP

Andrew Rudd BARRA

Laurence B. Siegel The Ford Foundation

Brian D. Singer, CFA Brinson Partners, Inc.

Lee R. Thomas Pacific Investment Management Company

Robert Trevor Mcquarie University

Ton Vorst Erasmus University

Arnold S. Wood Martingale Asset Management 
Stephen M. Horan, CFA

D. Bruce Johnsen

\section{The Welfare Effects of Soft Dollar Brokerage: Law and Economics}

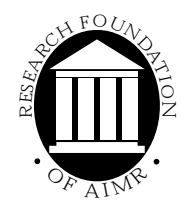

The Research Foundation of the Association for Investment Management and Research 


\section{Research Foundation Publications}

Active Currency Management

by Murali Ramaswami

Analysts' Earnings Forecast Accuracy in Japan and the United States

by Robert M. Conroy, Robert S. Harris, and Young S. Park

Bankruptcy Prediction Using Artificial Neural Systems

by Robert E. Dorsey, Robert O. Edmister, and John D. Johnson

Blockholdings of Investment Professionals

by Sanjai Bhagat, Bernard Black, and

Margaret Blair

Company Performance and Measures of Value Added by Pamela P. Peterson, CFA, and David R. Peterson

Controlling Misfit Risk in Multiple-Manager Investment Programs

by Jeffery V. Bailey, CFA, and David E. Tierney

Corporate Bond Rating Drift: An Examination of Credit Quality Rating Changes over Time

by Edward I. Altman and Duen Li Kao

Corporate Governance and Firm Performance by Jonathan M. Karpoff, M. Wayne Marr, Jr., and Morris G. Danielson

Country Risk in Global Financial Management by Claude B. Erb, CFA, Campbell R. Harvey, and Tadas E. Viskanta

Currency Management: Concepts and Practices by Roger G. Clarke and Mark P. Kritzman, CFA

Earnings Forecasts and Share Price Reversals by Werner F.M. De Bondt

Economic Foundations of Capital Market Returns by Brian D. Singer, CFA, and Kevin Terhaar, CFA

Economically Targeted and Social Investments: Investment Management and Pension Fund Performance

by M. Wayne Marr, John R. Nofsinger, and John L. Trimble

Emerging Stock Markets: Risk, Return, and Performance

by Christopher B. Barry, John W. Peavy III, CFA, and Mauricio Rodriguez

Equity Trading Costs

by Hans R. Stoll

Ethics, Fairness, Efficiency, and Financial Markets by Hersh Shefrin and Meir Statman

The Founders of Modern Finance: Their PrizeWinning Concepts and 1990 Nobel Lectures
Franchise Value and the Price/Earnings Ratio by Martin L. Leibowitz and Stanley Kogelman

Fundamental Considerations in Cross-Border Investment: The European View

by Bruno Solnik

Global Asset Management and Performance Attribution

by Denis S. Karnosky and Brian D. Singer, CFA

Initial Dividends and Implications for Investors by James W. Wansley, CFA, William R. Lane, CFA, and Phillip R. Daves

Initial Public Offerings: The Role of Venture Capitalists

by Joseph T. Lim and Anthony Saunders

Interest Rate and Currency Swaps: A Tutorial

by Keith C. Brown, CFA, and Donald J. Smith

Interest Rate Modeling and the Risk Premiums in Interest Rate Swaps

by Robert Brooks, CFA

The International Equity Commitment

by Stephen A. Gorman, CFA

Investment Styles, Market Anomalies, and Global Stock Selection

by Richard O. Michaud

Long-Range Forecasting

by William S. Gray

Managed Futures and Their Role in Investment Portfolios

by Don M. Chance, CFA

The Modern Role of Bond Covenants

by Ileen B. Malitz

Options and Futures: A Tutorial

by Roger G. Clarke

The Poison Pill Anti-Takeover Defense: The Price of Strategic Deterrence

by Robert F. Bruner

A Practitioner's Guide to Factor Models

Predictable Time-Varying Components of International Asset Returns

by Bruno Solnik

The Role of Risk Tolerance in the Asset Allocation

Process: A New Perspective

by W.V. Harlow III, CFA, and Keith C. Brown, CFA

Sales-Driven Franchise Value

by Martin L. Leibowitz

Time Diversification Revisited

by William Reichenstein, CFA, and Dovalee Dorsett 


\section{The Welfare Effects of Soft Dollar Brokerage: Law and Economics}


To obtain the AIMR Publications Catalog, contact:

AIMR, 560 Ray C. Hunt Drive, Charlottesville, Virginia 22903, U.S.A. Phone 804-951-5499; Fax 804-951-5262; E-mail info@aimr.org or

visit AIMR's World Wide Web site at www.aimr.org to view the AIMR publications list.

CFA $^{\circledR}$, CHARTERED FINANCIAL ANALYST $^{\mathrm{TM}}$, AIMR-PPS $^{\mathrm{TM}}$, GIPS $^{\mathrm{TM}}$, and Financial Analysts Journal ${ }^{\circledR}$ are just a few of the trademarks owned by the Association for Investment Management and Research. To view a list of the Association for Investment Management and Research's trademarks and a Guide for the Use of AIMR's Marks, please visit our Web site at www.aimr.org.

(C) 2000 The Research Foundation of the Association for Investment Management and Research

All rights reserved. No part of this publication may be reproduced, stored in a retrieval system, or transmitted, in any form or by any means, electronic, mechanical, photocopying, recording, or otherwise, without the prior written permission of the copyright holder.

This publication is designed to provide accurate and authoritative information in regard to the subject matter covered. It is sold with the understanding that the publisher is not engaged in rendering legal, accounting, or other professional service. If legal advice or other expert assistance is required, the services of a competent professional should be sought.

ISBN 0-943205-48-4

Printed in the United States of America

May 2000

\section{Editorial Staff \\ Bette Collins \\ Editor}

Lisa S. Medders

Assistant Editor

Jaynee M. Dudley

Production Manager

Donna C. Hancock

Production Coordinator

Lois A. Carrier

Composition 


\section{Mission}

The Research Foundation's mission is to identify, fund, and publish research that is relevant to the AIMR Global Body of Knowledge and useful for AIMR member investment practitioners and investors. 


\section{Biographies}

Stephen M. Horan, CFA, is assistant professor of finance at St. Bonaventure University in upstate New York. Prior to joining the faculty in 1996, he spent several years as a trader at Manning \& Napier Advisors, an independent money manager, and a short time as a retail broker for Quick and Reilly. In addition to receiving various awards for outstanding research, he co-authored the Forbes Stock Market Course and has published articles examining such topics as pension fund indexing and Roth invidivual retirement accounts in the Journal of Financial Research and the Financial Services Review. Professor Horan served as Education Chair for two years for the Buffalo Chapter of the New York Society of Security Analysts and currently is an abstract writer for The CFA Digest. He holds a Ph.D. in finance, with a concentration in economics, from the State University of New York at Buffalo.

D. Bruce Johnsen is an associate professor at George Mason University School of Law in Arlington, Virginia, where he teaches the law of investment management, law and economics, corporate finance, and competition policy. He has served on the faculties of the Wharton School at the University of Pennsylvania and the Department of Management at Texas A\&M University. In addition to receiving various research grants and awards for outstanding research, he has published articles in the Journal of Legal Studies, Journal of Law \& Economics, Journal of Finance, Journal of Financial Intermediation, Review of Financial Studies, in various law reviews, and in the popular press. From 1989 to 1991, he served as a financial economist in the Office of Economic Analysis at the U.S. Securities and Exchange Commission. He is currently a member of the board of trustees of the Virginia Retirement System. ${ }^{1}$ Professor Johnsen holds a Ph.D. from the University of Washington and a J.D. from Emory University.

\footnotetext{
${ }^{1}$ The views expressed in this monograph do not necessarily reflect those of the Virginia Retirement System.
} 


\section{Contents}

Foreword $\ldots \ldots \ldots \ldots \ldots \ldots \ldots \ldots \ldots \ldots \ldots$, viii

Preface $\ldots \ldots \ldots \ldots \ldots \ldots \ldots \ldots \ldots \ldots \ldots \ldots, \quad$ ix

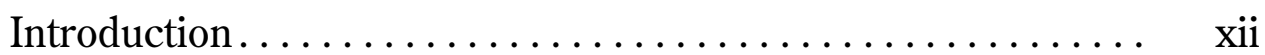

Chapter 1. The Legal and Regulatory Environment........ 1

Chapter 2. Agency Costs and Property Rights ......... 7

Chapter 3. The Unjust Enrichment Hypothesis .......... 13

Chapter 4. The Incentive Alignment Hypothesis . . . . . . . 17

Chapter 5. Tests and Findings $\ldots \ldots \ldots \ldots \ldots \ldots \ldots . . \ldots \ldots$

Chapter 6. Policy Analysis ....................... 47

Chapter 7. Summary and Concluding Remarks ......... 56

Appendix A. The Mutual Fund Manager's Share.......... 59

References.............................. 62

Selected AIMR Publications $\ldots \ldots \ldots \ldots \ldots \ldots \ldots \ldots . \ldots 6$ 


\section{Foreword}

Soft dollar brokerage is certainly one of the most controversial topics among investment professionals and government regulators, yet until now, little has been written that carefully and dispassionately evaluates the function of soft dollar brokerage. Stephen M. Horan and D. Bruce Johnsen go a long way to amend this situation with their excellent monograph.

Horan and Johnsen begin with a review of the historical setting within which soft dollar brokerage evolved, including the impact of shifting from fixed to negotiated commissions in 1975, and they describe with unusual clarity the current legal and regulatory environment. They artfully discuss the relevant legal and economic issues-namely, the principal-agent problem and property rights. Against this background, they introduce alternative hypotheses about the intended function and the consequences of soft dollar brokerage.

The first hypothesis, "the unjust enrichment hypothesis," holds that managers transfer wealth to themselves from their clients by shifting the costs of research to clients. As an alternative, Horan and Johnsen propose "the incentive alignment hypothesis," which is based on the principle that market participants will adopt the approach that best promotes their mutual interests.

Horan and Johnsen tested these competing hypotheses empirically. Their tests failed to show that soft dollar brokerage leads to inferior performance and lowers management fees, which one would expect if the unjust enrichment hypothesis were true. In contrast, their tests failed to refute the incentive alignment hypothesis, because the findings did not contradict its implications, which are that soft dollar use will produce superior performance with no effect on fees. The authors also point out that, although clients have the prerogative to proscribe soft dollar brokerage, few choose to do so, which further supports the incentive alignment hypothesis.

Bolstered by this evidence, Horan and Johnsen persuasively shift the burden of proof to those who would oppose soft dollar brokerage. Still, they recognize that in some cases, soft dollar brokerage can be abused. Thus, they offer several insightful policy recommendations to ensure that soft dollar brokerage achieves its desired result: aligning the incentives of managers and clients.

Horan and Johnsen have produced a thoughtful and fair-minded monograph about a topic that demands careful thought and fair analysis. Whether or not you concur with their methods or conclusions, you will certainly find their analysis enlightening and provocative. The Research Foundation is proud to present this monograph to you.

Mark Kritzman, CFA Research Director

The Research Foundation of the Association for Investment Management and Research 


\section{Preface}

As Ronald Coase recognized more than 20 years ago, whenever public policy commentators encounter a business practice they do not understand, they invariably condemn it as either anticompetitive or dishonest. ${ }^{1}$ The industrial organization literature is filled with examples of business practices that were resoundingly condemned when first observed but that, after careful and dispassionate analysis, are now widely viewed by economists as essential to efficient economic organization. Examples are exclusive dealing, horizontal territories, at-will termination clauses, resale price maintenance, and even vertical mergers. The pattern of rushing to condemn the unknown is not without consequence: In the interim, private fortunes may be lost, consumers and investors may be deprived of inestimable opportunities, and society's limited resources may be dissipated. Only by understanding why market participants find it privately profitable to use soft dollars on a large and sustained scale can we hope to accurately assess their welfare effects.

Our examination of the welfare effects of soft dollar brokerage is intended to provide a careful and dispassionate scientific analysis of the practice as the outcome of efficient economic organization. In a world in which market participants behave like textbook automatons, people have little reason to worry about choice of economic organization. In the real world, one characterized by self-interested parties capable of discovering and exploiting the most subtle opportunities for personal gain, efficient economic organization is essential to provide incentives that increase rather than decrease the size of the economic pie. Market participants are seldom able to provide a reasoned explanation for the forms of economic organization they choose, let alone defend the welfare effects of their choices in a public policy setting. This situation should come as no surprise: The competitive business environment selects survivors independently of their conscious motivations, and success often brings spontaneous imitation by those eager to gain a competitive advantage over less responsive rivals.

That private parties pursue their self-interest is recognized in law and economics as the source of both agency and transaction costs. Our specific concern is with the agency costs of professional portfolio management and the transaction costs of enforcing exclusive claim to private information about mispriced securities. Economic organization helps reduce these costs, but because economic organization is itself costly to design and implement, the

\footnotetext{
${ }^{1}$ For example, in 1992, Peter Rawlins, who was then chair of the London Stock Exchange, publicly condemned soft dollars simply because they fail to pass the "smell test."
} 
parties will never find complete elimination of agency and transaction costs to be in their mutual interest. Compared with an ideal world, some amount of inefficiency will persist. For example, investment managers may be allowed to pursue their narrow self-interests to some extent, and market interlopers may capture some of the value of managers' investment research. Nonetheless, competition ensures that no one consistently earns abnormal returns; investment manager wages, brokerage commissions, product prices, and security prices adjust to eliminate any surplus.

Within the broad category of economic organization, any number of arrangements are used to reduce the losses when parties pursue their private self-interests. One extremely important mechanism is agency law, which consists, for the most part, of basic fiduciary duties plus various default rules that apply when the parties have declined to reach explicit agreement to the contrary. The parties normally have the right and often the practical ability to contract around the default rules prescribed by agency law. Formal contracting, together with careful monitoring by the parties, provides another mechanism for reducing the losses from the private pursuit of self-interest.

Many readers will bristle at even the suggestion that investment managers are inclined to act contrary to their clients' interests. No doubt, most managers are scrupulously loyal to their clients, but even so, they will occasionally be ignorant of exactly which courses of action truly benefit their clients. In our view, efficient economic organization provides managers with the necessary guidance and may, in any event, be partly responsible for the generally high level of integrity found in the profession. In addition, market participants are keenly aware of their professional reputations, and within the prevailing norms of accepted business practice, they rely heavily on longterm relationships based on trust. Those who violate this trust risk being crushed by the relentless forces of an informed marketplace.

The question remains of exactly which business practices are acceptable. The realistic possibility remains that regulation-whether aimed at substantive conduct or disclosure-is necessary to prescribe the proper bounds of acceptability. But to conclude that every question of acceptability must be prescribed by regulation would be wrong. Voluntary private certification stands as both a realistic alternative and a helpful supplement to regulation. With such certification, a private third party with an established reputation defines the limits of acceptability and monitors and certifies compliance with those limits by its membership. Members who act outside the limits purposely put themselves at risk of being discovered, ostracized, and driven out of the business. 
Voluntary private certification has the obvious benefit of being noncoercive and, at the same time, providing a dynamic and evolving set of rules to which market participants can adhere. It also provides the prospect of competition from potentially superior rules. In many cases, private certification can respond more swiftly and appropriately than regulation to the ever-changing circumstances of time and place in a dynamic business environment. The quickening pace of market evolution with the advent of electronic trading and information retrieval merely exacerbates the practical limits to regulation as the exclusive arbiter of acceptable business practice and underscores the absolute necessity of placing greater reliance on voluntary private certification. 


\section{Introduction}

Soft dollar brokerage is a widely misunderstood practice whose effects on investor welfare have been the subject of undue controversy and offhand condemnation. Misunderstanding derives in part from the failure of most commentators to examine the practice from the standpoint of efficient economic organization. Our purpose here is to examine the welfare effects of soft dollar brokerage from both a legal and an economic perspective. ${ }^{2}$

Agency law, the current state of securities regulation, and the competitive business environment combine to shape market participants' choice of economic organization. Calls for tighter regulation of soft dollar brokerage raise the question of which set of laws, regulations, and market institutions best contribute to investor welfare. We believe the theoretical and empirical analysis presented here will enhance readers' understanding of soft dollar brokerage, and we suggest that any additional regulation be based on a reasoned appreciation for the subtleties of our analysis.

Soft dollar brokerage evolved out of the old fixed-commission system that prevailed on the New York Stock Exchange until 1975. Prior to that time, the NYSE prohibited its members from competing for brokerage business by offering to perform trades for their customers at commission rates less than the regulated minimum. In lieu of lower commissions, member-brokers offered various nonprice concessions to large institutional clients, such as mutual funds, pension funds, insurance companies, bank trusts, thrifts, and investment advisors, whose trading volume warranted quantity discounts. One popular form of nonprice concession was the research rebate, through which brokers made both proprietary in-house research and third-party research available free of charge to institutional managers. With the deregulation of fixed commissions in 1975, brokerage commissions became freely negotiable, and the average level of commissions fell dramatically. Yet, most brokers, led by the many new entrants to the industry, continued to bundle the cost of research and execution into a single commission. Where bundled research was provided by third parties, this arrangement became known as soft dollar brokerage, or simply soft dollars.

\footnotetext{
${ }^{2}$ Portions of this monograph originally appeared in D. Bruce Johnsen, Property Rights to Investment Research: The Agency Costs of Soft Dollar Brokerage, 14 Yale J. on Regulation 75 (1994). (C) Copyright 1994 by the Yale Journal on Regulation, P.O. Box 208215, New Haven, CT 06520-8215. Reprinted from vol. 11.1 by permission. All rights reserved. Because of space and exposition considerations, many citations in the original work have been omitted from this monograph.
} 
Poor understanding of soft dollar brokerage as a form of economic organization accounts for the controversy surrounding the practice. Soft dollars depart from the textbook norm of cash consideration between anonymous parties and, instead, constitute a form of in-kind rebate, with their use being confined almost exclusively to the principal-agent context of professional portfolio management. The beneficiaries of such a portfolio hire an investment manager as their agent to research, identify, and execute profitable portfolio trades. ${ }^{3}$ Having identified a likely trade, the manager uses a broker to search for the best available price and to execute the trade. The commission the manager pays goes into the price basis of the security and is thus implicitly paid by portfolio beneficiaries. In a typical soft dollar arrangement, the broker agrees to prepay a specific dollar value of the manager's research expenses out of a specific dollar value of future commissions that the manager promises to pay the broker for portfolio trades. ${ }^{4}$ The manager receives research inputs up front from third-party "research originators," whom the broker pays in cash. The manager thereafter directs portfolio trades to the broker to generate the promised commissions. Because the commission rate exceeds the cost of pure execution, the manager is said to "pay up" for soft dollar research.

Critics of the practice argue that soft dollars tempt managers to enrich themselves unjustly at the expense of portfolio beneficiaries. They claim that soft dollars compromise a manager's fiduciary duty to portfolio beneficiaries by bundling the costs of investment research and portfolio trades into a single brokerage commission paid implicitly by the portfolio rather than explicitly by the manager. One criticism is that because soft dollars allow managers to pay up for brokerage, managers will agree to excessively high commissions to compensate for the research inputs they receive at the expense of brokers (and ultimately portfolio beneficiaries). Another criticism is that soft dollars encourage managers to "churn" the portfolio (trade more than necessary) to generate research rebates. The final criticism is that, having received research in advance, managers may develop a misplaced sense of obligation to continue using brokers whose execution quality falls below an acceptable level; being unwilling to terminate the broker, a manager may pay inadequate attention to monitoring the broker's execution quality.

\footnotetext{
${ }^{3}$ Unless the context suggests otherwise, we use the term "investment manager" to denote the party who provides investment advisory services to principals.

${ }^{4}$ The usual soft dollar formula is expressed as a ratio of commission dollars to research together with the total commissions to be generated by the manager. For instance, a 2-to- 1 ratio means the manager promises to direct $\$ 2.00$ in trading commissions to the broker for each $\$ 1.00$ the manager receives in research products. The parties determine the commission rate per share when the manager goes to order the trade or even after the broker executes it.
} 
In any agency setting with multiple principals, portfolio beneficiaries face what is known as a "collective action problem" in monitoring their managers. Because the gains from monitoring are shared equally by all portfolio beneficiaries, no individual beneficiary has sufficient incentive to incur the costs of monitoring the manager's brokerage practices. Thus, the manager's use of soft dollars is virtually invisible.

In addition to calling into question the propriety of soft dollar brokerage, many commentators question whether investment research, in its entirety, has any positive effect on portfolio returns. The conclusion that it does not received early support from several empirical studies that found the gross risk-adjusted returns on actively managed mutual funds to be virtually identical to the returns of a passively managed market index such as the S\&P 500 Index (see, for example, Jensen 1968). Returns fell short of the index after active management fees were deducted. The inference from these studies is that all investment research represents pure waste, and the conclusion is inescapable that both active management and soft dollar brokerage make portfolio beneficiaries worse off. Recent empirical work contradicts these findings. Consensus is emerging that actively managed portfolios earn risk-adjusted returns against the S\&P 500 at least sufficient, on average, to cover the added research and management costs (Ippolito 1989; Grinblatt and Titman 1989; Gruber 1996; see Malkiel 1995 for contrary results). ${ }^{5}$ This conclusion supports the view that some amount of investment research does indeed have social value and that by encouraging investment research, soft dollar brokerage may increase investor welfare.

To the alarm of its critics, soft dollar use has grown considerably in the past two decades-by some accounts, to as much as $\$ 1$ billion annually in the United States alone (Inspection Report 1998, Note 1). In response, calls for further regulation of soft dollars and even outright prohibition have mounted. Widespread concern over soft dollar use led the SEC in 1994 to identify soft dollars in its Market 2000 Study as one of the subjects to be

\footnotetext{
${ }^{5}$ The view that investment managers can earn positive risk-adjusted returns on average or that certain managers can predictably do so on a consistent basis has been challenged on theoretical and empirical grounds. Roll (1978), for example, argued that risk-adjusted returns cannot be truly measured unless the benchmark portfolio is mean-variance efficient, which is impossible to know (at the very least, the S\&P 500 benchmark portfolio used in the studies mentioned here is most certainly not mean-variance efficient). Lehman and Modest (1987) showed that measures of risk-adjusted performance are indeed very sensitive to the choice of benchmark portfolio. Recently, researchers have come to different conclusions about the performance of managed portfolios. In any event, active portfolio management persists in a competitive marketplace, which suggests that it provides both private and social benefits to the large number of investors who use it as a store of wealth.
} 
investigated. In September 1998, the SEC's Office of Compliance, Inspections and Examinations (which we shorten to Office of Compliance for the remainder of this monograph) responded with so-called sweep inspections of soft dollar practices by a sample of broker/dealers, investment advisors, investment companies, and unregulated entities (Inspection Report 1998). The Inspection Report identified a number of cases in which investment managers and broker/dealers used inappropriate products or failed to provide adequate disclosure. Apparently, civil (and possibly criminal) cases are pending. Our information is that this threat has caused a substantial decline in the use of soft dollar brokerage.

This monograph examines soft dollar brokerage practices as the outcome of efficient economic organization. Chapter 1 describes the legal and regulatory environment in which soft dollar brokerage occurs. Chapter 2 examines the problem of agency costs in delegated portfolio management and describes the problems of property rights that investment managers face when in possession of private information. Chapter 3 outlines what we call "the unjust enrichment hypothesis," which we have distilled from academic commentaries, the financial press, and various administrative rulings by the SEC. According to this hypothesis, agency costs prevent portfolio beneficiaries and investment managers from organizing their relationship efficiently and soft dollar use is a reflection of the associated dissipation of portfolio value.

In Chapter 4, we present an alternative explanation for soft dollar brokerage, "the incentive alignment hypothesis." We begin by showing that the criticisms of soft dollars apply to any brokerage arrangement in which nonexecution services are bundled, implicitly or explicitly, into trading commissions. We then note that delegated portfolio management suffers from having several layers of agents. Portfolio beneficiaries hire investment managers to identify profitable portfolio trades, and in turn, managers must hire and monitor brokers to execute trades. Agency theory suggests that managers will have too little incentive to monitor brokers and that brokers, as agents, will have too little incentive to diligently execute trades. The result is that interlopers are likely to capture much of the value of any private information identified by managers, which would substantially reduce the returns to active management. Moreover, agency theory suggests that investment managers will have too little incentive to identify profitable portfolio trades if they are required to pay all research expenses out of their own pockets-because they receive only a fraction of the associated benefits while bearing a disproportionate share of the costs. According to the incentive alignment hypothesis, to the extent that the broker provides soft dollar research credits to the manager in advance of trading, soft dollars provide an effective performance bond for the quality of 
brokerage execution and thereby allow otherwise unfamiliar parties to establish an effective basis for trust. At the same time, by bundling investment research into the trading commission paid by portfolio beneficiaries, soft dollars efficiently subsidize the manager's search for profitable trades. Seen in this light, soft dollars constitute an efficient form of economic organization that reduces rather than increases the agency costs of delegated portfolio management.

The unjust enrichment and incentive alignment hypotheses are equally plausible in terms of their internal logic and can thus be judged only by how consistent their implications are with the activities observed in a competitive marketplace. Chapter 5 derives testable implications for these hypotheses, describes the database we used in testing, and presents our empirical findings. Although many empirical tests could differentiate the two hypotheses, data limitations restricted us to an examination of the relationship between soft dollar brokerage and manager performance and between management fees and brokerage commissions. On average and after adjusting for market risk and other confounding factors, our evidence suggests that portfolio returns are positive and increasing when soft dollars are used and that there is no systematic relationship between management fees and brokerage commissions. Although by no means conclusive, these findings tend to refute the unjust enrichment hypothesis and to support the incentive alignment hypothesis. The findings suggest that more empirical work must be done before the incentive alignment hypothesis can be rejected.

Chapter 6, which discusses the implications of our empirical findings for policy makers, focuses specifically on the implications for disclosure reform, voluntary certification, principal trading, electronic trading, and electronic information processing and retrieval.

Chapter 7 provides a summary, adds some concluding remarks, and discusses the implications of our analysis for practicing financial analysts. 


\section{The Legal and Regulatory Environment}

During most of the history of the U.S. securities industry, investment research was produced primarily by the small number of full-service brokerage firms that dominated the New York Stock Exchange (NYSE). These firms made their research available to favored clients by bundling the costs of research and trade execution together into a single, regulated brokerage commission. Not until the late 1960s and the rise of professional portfolio management did investment research and trade execution begin to be unbundled and the dominance of the full-service brokerage houses over securities trading begin to wane. Brokerage commissions on the NYSE were entirely deregulated in May 1975, and unbundling began to occur in earnest with the rise of third-party research and soft dollar brokerage.

\section{A Brief History}

Formal restrictions on securities trading began in the United States in 1792 with the formation of the Buttonwood Agreement, an association of stockbrokers that eventually developed into the NYSE. Several commentators have noted that this agreement, which survived largely intact until 1975, functioned much like a naked price-fixing agreement by providing explicitly for minimum commissions and preference to NYSE members in all transactions. Any doubt about the compatibility of NYSE minimum commissions with the antitrust laws was laid to rest by the creation of the Securities and Exchange Commission shortly after the stock market crash of 1929, the passage of the Securities Act of 1933, and the passage of the Securities Exchange Act of 1934. Through these acts, Congress placed supervision of the NYSE and other self-regulatory organizations (SROs) in the hands of the SEC. Within the decade, Congress had provided for creation of the National Association of Securities Dealers to conduct over-the-counter trading. The SEC came to supervise the NASD and the OTC dealer market just as it had supervised other SROs. By the end of the decade, Congress had passed the Investment Advisers and Investment Company Acts of 1940 to regulate professional portfolio management.

Throughout the early history of the industry, most securities were held and traded by private investors through individual brokerage-house 
accounts. With passage of the Investment Company Act, securities ownership by open-end investment companies (mutual funds) grew considerably. Between 1940 and 1975, open-end funds grew in total dollar value from approximately $\$ 448$ million to approximately $\$ 49$ billion. Pension portfolios experienced similar growth, increasing in total dollar value from approximately $\$ 18$ billion in 1950 to nearly $\$ 400$ billion in 1975 . Moreover, the share of outstanding U.S. corporate common stock held by these and other institutions increased from about 23 percent in 1955 to more than 33 percent in 1980. No doubt the growth of institutional ownership was made possible in part by emerging opportunities for investment research brought on by the ever-accelerating electronics revolution. Possibly because of scale economies in trading, professional investment managers tended to trade in relatively large blocks for which per share execution costs are believed to have been substantially lower than average. By the late 1960s, large block trading (transactions involving more than 10,000 shares) by investment managers had begun to transform the industry. As one academic noted, "[B] efore 1960, less than $2 \%$ of NYSE volume resulted from block trades. . . By 1980 block trading accounted for about $27 \%$ of NYSE share volume” (Jarrell 1984, p. 279).

The trend toward institutional ownership was instrumental in the deregulation of fixed commissions. As institutional managers became less dependent on Wall Street's full-service firms for investment research, brokers increasingly turned to nonprice competition as a response to fixed minimum commissions. Indeed, in the 15 years preceding deregulation, nonprice competition by NYSE brokers in the form of "give-ups" and "reciprocals" (including various types of research rebates) proliferated. This activity accounted for roughly 60 percent of commissions on institutional-size orders. In addition, many institutions simply bypassed the NYSE altogether, either by trading NYSE-listed securities on various regional exchanges through what was known as the Third Market or by arranging direct trades with other institutions through proprietary trading systems on the Fourth Market.

In 1968, at the behest of the SEC, the NYSE responded to the loss of trading volume by allowing a 7 percent discount on orders exceeding 1,000 shares. At the same time, however, the NYSE prohibited its members from providing give-ups or engaging in off-board trading in NYSE-listed stocks. The response by many investment advisors was to integrate vertically into brokerage by acquiring exchange memberships or member affiliates in an effort to capture the full discount from block trading. This trend toward vertical integration further eroded the NYSE's grip on the industry and resulted in a series of SEC rulings prescribing negotiated commissions on the portion of an order above a set minimum dollar value. Over the years, the SEC 
successively lowered this minimum until May 1975 when commissions were made entirely negotiable as part of the Securities Acts Amendments to the Securities Exchange Act of 1934. The result was a dramatic drop in brokerage commission rates and a surge in NYSE trading volume.

In addition to providing for negotiated commissions, the 1975 amendments also added Section 28(e), the "paying up amendment," to the Exchange Act. Section 28(e) was designed to allay widespread concern by investment managers that their common law and statutory duties of best execution would limit them to paying only the lowest available commissions for portfolio brokerage regardless of execution quality or the value of any research services they received. Part (1) of Section 28(e) states in part:

No person [who exercises] investment discretion with respect to an account shall be deemed to have ... breached a fiduciary duty ... solely by reason of having caused the account to pay a member of an exchange, broker, or dealer an amount of commission ... in excess of the amount of commission another member of an exchange ... would have charged ... if such person determined in good faith that [it] was reasonable in relation to the value of the brokerage and research services provided. ${ }^{1}$

Although Section 28(e) mandates fairly broad protection to portfolio managers in allocating brokerage, any formal contractual commitment to patronize a particular broker necessarily falls outside its safe harbor. Exclusive-dealing contracts are surely prohibited, but even in the absence of a formal agreement, any investment manager found to have placed an excessive share of trades with a single broker risks legal action by the SEC and portfolio shareholders. The exact scope of Section 28(e) protection has evolved over the years through a number of SEC letter rulings, cases, and administrative releases. This evolution has had substantial influence on the current institutional structure of securities brokerage and investment management.

\section{The Current Setting}

With deregulation, Wall Street suffered a sobering shakeout. Commissions declined considerably, from perhaps 40 cents a share to $5-10$ cents a share. NYSE seat prices declined in value by roughly 50 percent, in spite of a tremendous increase in trading volume. The brokerage industry experienced an alarming merger wave, although by any reasonable standard, concentration in the industry remained fairly low. The full-service houses began to diversify away from the equity-agency business. Among those hardest hit by deregulation were the medium-size firms that had specialized in providing

${ }^{1} 15$ U.S.C. $§ 78 b b$ (e) (1998) (as amended). 
proprietary in-house research to institutional clients. As one observer put it, "the reduction in the demand for research services that accompanied deregulation caused the demise of these research firms" (Jarrell 1984, p. 303). Leading the move toward lower commissions was a proliferation of no-frills discount brokers. In the next few years, discount brokers' market share increased from less than 0.5 percent to roughly 6 percent. Protected from fiduciary suits by Section 28(e)'s safe harbor, professional investment managers began to use soft dollar brokerage to acquire third-party research on a significant scale.

In contrast to the brokerage industry, the investment management industry flourished following deregulation. Total pension portfolio assets had risen to nearly $\$ 2.5$ trillion by 1990 ; total investment company assets had grown to more than $\$ 1$ trillion. Institutional holdings of corporate common stock surpassed 50 percent, and institutions accounted for approximately 72 percent of NYSE share volume (Schwartz and Shapiro 1992). The decline in commissions not only brought a predictable increase in trading volume and asset holdings by institutional investors; it also triggered a dramatic rise in portfolio turnover, which more than tripled between 1975 and 1984.

The available evidence indicates that with higher turnover came growth in soft dollar use. Several commentators have estimated that by 1990, 30-50 percent of all trades on the NYSE involved the provision of third-party research as part of some form of soft dollar arrangement. Annual soft dollar brokerage commissions for 1989 were thought to be in excess of $\$ 1$ billion. The steady rise in soft dollar use and the associated decline in commissions correlated with an increase in the ratio of research to brokerage included in soft dollar commissions. The SEC's Inspection Report of 1998 suggests that total soft dollar use has remained roughly constant since 1989.

One of the SEC's first postderegulation rulings under Section 28(e) was a 1976 interpretive release finding that the safe harbor does not apply to research products that are "readily and customarily available ... to the general public on a commercial basis." Although the SEC has since amended this interpretation, for many years, the ruling prohibited managers from receiving such basic research tools as Quotron machines, computer hardware, some forms of computer software and databases, and other items necessary for effective portfolio management. By its terms, the interpretation appeared to exclude most generic research products sold in the market by third-party research vendors.

The SEC's next important ruling considered Section 28(e)'s limitation to those who exercise "investment discretion" on behalf of a managed account. In Foley \& Lardner, the SEC staff ruled that a corporate pension plan sponsor 
(the corporation itself) receives no safe harbor protection when it directs its outside investment managers to send portfolio brokerage to a specific soft dollar broker in exchange for research services to be received by a plan sponsor. The SEC reached this decision because the plan sponsor was found to have exercised no investment discretion over pension assets.

Shortly after this decision, the SEC clarified the meaning of the phrase "provides research and brokerage" in Section 28(e), thus settling lingering uncertainty over whether the broker must produce the research in-house. According to the SEC, the broker need only retain the

legal obligation to a third-party producer to pay for the research (regardless of whether the research is then sent directly to the broker's fiduciary customer by the third party or instead is sent to the broker who then sends it to its customer). ${ }^{2}$

Not until 1986 did the SEC amend its "readily and customarily available" standard for the exclusion of research from safe harbor. In response to the "changing array of research products and the impact of new technology on brokerage practices," the SEC relaxed the horizontal scope of Section 28(e) protection to include any research product that "provides lawful and appropriate assistance to the money manager in the performance of his investment decision-making responsibilities." This ruling clearly allows generic research products to be included in the safe harbor and was followed by considerable expansion in soft dollar brokerage and third-party research, largely at the expense of the full-service houses. ${ }^{3}$ At the same time, however, the SEC concluded from the legislative history of Section 28(e) that the investment manager must keep "adequate books and records" to overcome the burden of proving good faith in the manager's brokerage allocation decisions.

The most significant recent SEC decision regarding Section 28(e)'s safe harbor was a 1990 letter ruling in response to an inquiry from the U.S. Department of Labor. Before taking enforcement action in several cases pending under the Employee Retirement Income Security Act, the DOL requested the SEC's opinion on whether the safe harbor applies to OTC stocks and fixed-income securities, which are traded primarily by dealers on a principal basis. By its text, Section 28(e) covers trades sent by the manager

\footnotetext{
${ }^{2}$ This clarification is in the National Association of Securities Dealers, Inc., Exchange Act. Rel. No. 17.371 (December 12, 1980).

${ }^{3}$ The SEC's new standard was also curiously restrictive; it narrowly construed the vertical scope of what it considers to be research, stating by way of example that "where a money manager is invited to attend a research seminar or similar program, the cost of that seminar may be paid for with commission dollars. Non-research aspects of the trip, however, such as travel costs, hotel, meal and entertainment expenses, are not within the safe harbor."
} 
to a "broker or dealer," but in reference to the trader's compensation, it mentions only commissions, not markups or markdowns. In the narrow sense of "commissions," only brokers earn them; dealers, as principals, earn markups and markdowns. Because Congress passed Section 28(e) to mitigate problems caused specifically by the unfixing of commissions, the SEC found that the safe harbor does not apply to dealer transactions. This decision brought the burgeoning use of soft dollars in fixed-income and OTC equity transactions to a grinding halt.

These rulings under Section 28(e) define a limited refuge for those interested in using soft dollars to bundle brokerage and third-party research into a single commission. Prior to deregulation, this kind of bundling was a predictable response to fixed minimum commissions. The question is, then: Why bundle? Why not price and transact trade execution and research separately? As then Commissioner Joseph Grundfest asked during a 1989 SEC Roundtable discussion on soft dollars, "Why is it that in this situation, the folding green stuff most of us are familiar with appears not to work?” (Maher 1989, p. 21).

Concern that the bundling of third-party research together with execution might compromise investment managers' loyalty to their clients led the SEC's Office of Compliance to perform "limited on-site inspections" of the soft dollar activities of 75 broker/dealers and 280 investment advisors and investment companies from November 1996 through April 1997 (Inspection Report 1998). These inspections revealed various instances of improper use of thirdparty products, deficient record keeping, and inadequate disclosure by investment advisors. The Office of Compliance responded by requesting that the results of the report be published to clarify the proper scope of Section 28(e)'s safe harbor to the advisory community, that the commission provide further guidance as to the scope of the safe harbor, that the commission adopt record-keeping requirements to provide greater accountability for soft dollar transactions and allocations, that the commission modify the standard advisor's disclosure form to require more detailed disclosure of nonresearch products received by investment advisors, and that the commission encourage advisors and broker/dealers to strengthen their internal control procedures regarding soft dollar practices. 


\section{Agency Costs and Property Rights}

We explore in this chapter two thorny problems that the use of soft dollars raises. First, we describe what the law, economics, and finance literatures call the principal-agent problem, on which the widespread criticism of soft dollars implicitly relies. Second, we discuss the problem of property rights that arises from the private information generated by professional portfolio managers' investment research.

\section{The Principal-Agent Problem}

The principal-agent problem arises because an agent, such as an investment manager, has only a partial stake in the profitability of the enterprise of a principal, such as a plan beneficiary, whereas the costs to the principal of perfectly monitoring the agent's activity are prohibitive. As a result, the agent may shirk (fail to carry out the agent's duties) or consume too many of the principal's resources in the form of perquisites, so the parties' joint wealth will fall short of what it could be.

Agency costs are likely to arise whenever a principal delegates discretion to an agent. According to Jensen and Meckling's seminal 1976 scholarly article on the subject, agency costs consist of monitoring costs by the principal, bonding costs by the agent, and a residual loss. In their words:

The principal can limit divergence from his interest by establishing appropriate incentives for the agent and by incurring monitoring costs designed to limit the aberrant activities of the agent. In addition, in some situations it will pay the agent to expend resources (bonding costs) to guarantee that he will not take certain actions which would harm the principal or to ensure that the principal will be compensated if he does take such actions. However, it is generally impossible for the principal or the agent at zero cost to ensure that the agent will make optimal decisions from the principal's viewpoint. In most agency relationships the principal and the agent will incur positive monitoring and bonding costs (non-pecuniary as well as pecuniary), and in addition there will be some divergence between the agent's decisions and those decisions which would maximize the welfare of the principal. The dollar equivalent of the reduction in welfare experienced by the principal due to this divergence is also a cost of the agency relationship ... the "residual loss." (p. 308) 
As in all agency arrangements, agency costs limit the advantages of professional investment management and reduce the wealth of portfolio beneficiaries compared with what their wealth would be in a perfect world in which agency costs were absent. Virtually all agency arrangements create value on a variety of interrelated dimensions; price, quality, and timeliness are a few that are normally subject to an agent's discretion. An agent who pays a higher-than-average price on behalf of the principal may also receive higher quality or more timely performance, so conduct that appears to be a source of agency costs when looked at from one angle might reduce aggregate agency costs when its effects are examined from all angles. Moreover, any time agency costs impede exchange, the parties can increase their joint wealth by organizing their relationship more efficiently.

Excessive or careless trading by a portfolio manager surely constitutes one source of agency costs. But other sources exist, some of which arise from the inherent problems managers have in capturing the value of their investment research for portfolio beneficiaries.

\section{The Property Rights Problems}

The private information that results from investment research by professional portfolio managers presents unique property rights problems. By carefully examining the nature of these problems, and the transaction costs they engender, we provide insight into soft dollars as an efficient form of economic organization.

We use the term "property rights" in a broad economic sense to include the expectation, not necessarily legally enforceable, of being able to capture value flows. In many cases, private parties successfully (although imperfectly) organize their business relationships to capture these value flows when the law provides inadequate protection. The chosen form of economic organization encourages productive investment, much as a patent does, by assuring that the investing party will capture the associated returns personally or, if the investor is a fiduciary, will capture them for the investor's principal(s). Economic organization is costly, of course, and we consider these costs to be transaction costs. ${ }^{4}$

\footnotetext{
${ }^{4}$ We define "transaction costs" broadly as the costs of defining, enforcing, and transferring ownership claims. This definition subsumes the narrow view normally held by financial market participants, which is that transaction costs consist strictly of the direct and indirect costs of trading securities.
} 
Because the structure of the securities industry has changed dramatically from the days before deregulation, we examine how the provision of investment research and the nature of the associated property rights problems have evolved over time.

Under the old fixed-commission system, full-service brokers produced investment research in-house, bundled their research conclusions with brokerage services, and charged a single commission to cover the costs of both functions. Because there are never enough good research conclusions to go around, brokers had to select which clients would get them first. Under the old system - and to a lesser extent under the new system-full-service brokers discriminated in favor of preferred clients by calling them first with news of the most recent trading opportunities identified by their in-house investment research. According to one commentator:

In the old days, Wall Street research was a more exclusive affair, and institutions had a greater need to keep close trading ties with brokers to stay informed. Whenever a broker unearthed a new investment insight, it was the customers who generated the most commission revenue who were assured of the "first call."

Today, with instantaneous communications, computerized information services and automated trading systems, research doesn't stay proprietary for very long. That means not only that it's harder and more expensive to stay ahead in the Wall Street research game, but also that the resulting product tends to be a more perishable, less lucrative commodity. (Donnelly 1991)

Although some clients were favored over others, those clients had to pay more to gain favor. The favoritism of individual brokerage-house accounts led clients to compete to be favored in the allocation process, with the result that clients dissipated any surplus value they stood to receive. Few individual clients had the bargaining power to command above-normal returns, and the transaction costs of forming bargaining coalitions with other clients were no doubt prohibitive.

The property rights problem created by proprietary investment research has at least two manifestations beyond favoritism. The first, a measurement problem, results from the high cost to investors of assessing the value of investment research conclusions. The problem with trading this kind of information in a nonrecurring setting is that the buyer can never know with certainty whether the trading opportunity has any value (and for the seller to provide a guarantee would be extremely difficult). To verify the value of the research, the buyer would have to devote considerable time and attention to measuring its value. In the extreme case, the buyer would have to completely reproduce the research, which would eliminate any gains from specialized 
intermediation. The measurement problem makes transacting for proprietary investment research difficult and accounts for the heavy reliance market participants place on long-term relationships based on loyalty and trust.

The second problem is leakage. When investors acquire superior information, they must maintain anonymity, because the market is filled with potential interlopers eager to mimic their trades. In the extreme case, brokers themselves may trade before the client can (that is, front-run) or purposely tip off associates. In the less extreme case, the interloper may simply be an astute, watchful market participant who is capable of taking advantage of the slightest sign of carelessness by the broker. Either way, the manager stands to lose some or all of the value of the investment research because of the impact on the security's price of others who have inferred some or all of the superior research information. The more talented the manager is believed to be at identifying mispriced securities, the more severe the leakage problem will be and the more likely it will be that the prices in the manager's trades will suffer.

The old fixed-commission system minimized these property rights problems by using extra-legal sanctions against interlopers. "Club" membersthe full-service brokerage firms that dominated the NYSE-invested heavily in their business reputations and built relationships by dealing repeatedly with other club members and loyal clients. Anyone caught interloping, leaking information, or selling worthless investment research risked being ostracized and losing the benefits that accrued to continued club membership and a long course of dealing. Under the circumstances, the old system was probably an efficient form of organization that, when compared with alternative systems and given the state of the art in information processing at the time, at least partly succeeded in establishing rights to the trading opportunities. Socially, the benefit of establishing property rights to investment research is that clearly defined rights encourage the beneficiary to make the investments necessary to identify mispriced securities in the first place, which ultimately leads to more efficient resource allocation.

The rise of investment companies and other professionally managed portfolios in the 1950s and 1960s, together with the advent of financial market deregulation, changed these ways of doing business. For example, open-end mutual funds and other pooled investment vehicles have the remarkable advantage over individual brokerage-house accounts of averting the competition among clients to gain the favor of investment managers. This advantage arises because portfolio beneficiaries have a common claim to an undivided pool of assets. For a mutual fund manager to favor one investor over another 
in a given portfolio is next to impossible. ${ }^{5}$ As a result, mutual fund investors have no reason to engage in costly competition to gain favor, so mutual funds and other investment companies avoid the favoritism problem.

The transaction cost advantages that institutional managers enjoyed over small private investors before deregulation gave managers an advantage in bargaining with full-service brokers for give-ups, reciprocals, and other nonprice concessions. Over time, institutional managers became less dependent on full-service brokers for in-house investment research, which allowed them to take advantage of low-cost off-board trading on the regional exchanges. At the same time, the electronics revolution changed the fundamental character of investment research and accelerated the relative decline of full-service brokerage. The consensus among commentators is that the electronics revolution and the information age it ushered in led to increased specialization and a notable dispersion of the investment research function. Some market analysts have concluded that the driving force behind deregulation was the electronics revolution. Others, however, maintain that it was the rise of the regional exchanges.

During its first 150 years, the NYSE faced and overcame recurring bouts of competition with regional exchanges. Even with fixed minimum commissions, the NYSE apparently succeeded in offering a superior product. Why did it take more than 150 years for competing exchanges to erode the NYSE's dominance?

Our belief is that the superior product the NYSE once offered was investment research and that the electronic revolution gave investment managers effective access to viable alternatives to in-house research by fullservice brokers. Only with the rise of professionally managed portfolios did efficient use of these alternatives begin to occur on a significant scale.

Under the old system, investment research tended to be in the nature of outputs-that is, proprietary conclusions about profitable trading opportunities-that were virtually impossible to transact separately in the market because of the problems of measuring their value and preventing

\footnotetext{
${ }^{5}$ When a private money manager operates multiple accounts, the problem of favoritism moves to a new level. Our evidence suggests, however, that managers often go out of their way to treat separate accounts equally. In some cases, the manager formally gives each account a pro rata claim to an undivided pool of assets. The problem of favoritism also arises in the case of a central advisor of a mutual portfolio complex who operates a number of individual, legally separate portfolios. This advisor is in a position to favor one portfolio over the others. This problem may be mitigated in some portfolio complexes by rules allowing shareholders to convert freely among the various portfolios in the complex. Finally, to the extent investment managers continue to rely on full-service brokers for some in-house investment research, the old-style favoritism between some brokers and their clients no doubt persists.
} 
leakage. Full-service brokers assembled information from private sources with the help of a small number of well-heeled participants and distributed the conclusions to these participants in order of their priority in the brokers' customer rankings.

Since deregulation, the investment research traded in the market has tended to be in the nature of inputs provided by third parties, such as computer software, hardware, research reports, databases, and analytical programs. Investment managers assemble these inputs to arrive at their own outputs, consisting of conclusions about profitable trading opportunities. Under the new system, investment managers gather information from widely dispersed sources, at least some of which are public in nature, and use their own knowledge and skill to arrive at proprietary conclusions.

The rise of professional portfolio management is a striking example of widespread vertical disintegration of the firm. Institutional managers have taken on many of the investment research functions that in the past were performed exclusively by full-service brokers. Eventually, the vertical disintegration of research and its reintegration into investment management tipped the balance of competing political interests in favor of deregulation.

The new system that has evolved out of deregulation allows investors to avoid the favoritism and measurement problems of the old system by placing their money with professional portfolio managers, but it probably aggravates the leakage problem and adds the principal-agent problem that is inherent in professional portfolio management. 


\section{The Unjust Enrichment Hypothesis}

The notion that soft dollars allow managers to unjustly enrich themselves by transferring wealth from their clients relies on the normative belief that managers should bear all the costs of investment research; essentially, managers should pay for research in cash out of their own pockets. The assumption behind this belief is that managers' advisory fees provide them with full compensation for the costs of investment research.

In this view, a manager's ability to use soft dollars covertly to transfer research costs to the portfolio compromises the manager's duty of loyalty to portfolio beneficiaries. This view was recently summarized by SEC Chair Arthur Levitt as follows:

Soft-dollar arrangements can create substantial conflicts of interest between an adviser and its clients. For example, advisers may cause their clients to pay excessive commission rates, or may overtrade their clients' accounts simply to satisfy soft-dollar obligations. Soft-dollar arrangements may also result in inferior executions when advisers direct trades to the wrong broker to satisfy a soft-dollar obligation. (Taylor 1995)

The SEC also has warned of these conflicts of interest. In discussing the protections an investment manager enjoys under Section 28(e) in using soft dollar brokerage, the SEC emphasized that the manager must "exercise the utmost care to avoid improperly enriching himself at the expense of his client."

Despite being based on a normative belief, the unjust enrichment hypothesis can also be formulated as a scientific hypothesis premised on the agency problem inherent in professional portfolio management. The agency problem can manifest itself in a number of ways because of costly contracting and monitoring. First, the manager might treat the research products purchased with soft dollars as a free good and use more of them than their cost to clients would justify. Second, the manager might direct trades to soft dollar brokers to whom the manager is indebted for research, even though these brokers provide poor execution quality. Finally, the manager might churn the account or agree to excessively high brokerage commissions to compensate for the research the manager should pay for.

The consensus among financial market commentators is that many of the research products managers receive through soft dollar arrangements are 
worthless. For example, Logue (1991), in discussing transaction costs as a pressing issue in pension management, observed that soft dollars

make buying a lot of wild and useless analysis very nearly painless, because the true value of the service is masked. Given that the commissions are going to be generated anyway, the purchaser may treat what is purchased as essentially free, [so] the product or service does not pass a cost-benefit standard on its own. (p. 270)

Logue emphasized that "commissions are only one part of transaction costs." Market impact costs, he correctly pointed out, must also be included in the calculus. The failure of a pension plan sponsor or investment manager to account for these costs can have a substantial effect on total transaction costs and, ultimately, on portfolio performance:

The costs of extremely poor trade executions can far exceed the cash value of the research service. Thus in many instances it is likely true that paying cash for what is truly needed and systematically selecting the broker likely to produce the lowest total transaction cost may be far less costly than the soft-dollar arrangements that may push a sponsor [or manager] to deal with a brokerage firm which has very high market impact costs. (p. 271)

Others take issue with Logue's assumption that "the commissions are going to be generated anyway.” A number of commentators have insisted that soft dollars give the manager an incentive to churn the portfolio to generate additional brokerage commissions and the soft dollar rebates that go with them. Pozen (1976), writing shortly after the deregulation of brokerage commissions, stated that money managers "have an incentive to make an excessive number of trades for their clients' accounts under soft dollar payments ... [and to] maximize the flow of securities research at their clients' expense” (p. 956). More recently, some have described the churning problem in explicit cost-benefit terms:

In an environment without Section 28(e), research would be purchased until the last hard dollar spent for the research equaled the value of that research to the clients. Any additional research would benefit the clients less than its cost, and thus would be an unreasonable expenditure. Thus, if one argues that managers are more willing to buy additional research with soft dollars than they would using hard dollars, then one admits that the purchases are unreasonable in relation to their cost. (Burgunder and Hartmann 1986, p. 176)

Consistent with the widespread consensus among financial market commentators, the SEC seems to have settled on the belief that soft dollars create real conflicts of interest. The SEC's view is that soft dollars tempt managers to churn their portfolios to pay their research bills and enrich themselves at the expense of portfolio beneficiaries, although to our knowledge little or no 
systematic empirical support exists for this conclusion. A clear early statement by the SEC on this issue is found in Fund Monitoring Services, Inc., an SEC letter ruling. Fund Monitoring Services was a third-party research originator that had developed a service to evaluate the relative performance of individual investment managers. FMS set up soft dollar accounts for pension plan sponsors and the advisors of portfolio complexes to provide them with the service. The agreement required that each portfolio manager direct a minimum amount of commission business over the course of the accounting year to any of the brokers on the FMS-approved list. The managers were free to negotiate commissions with the chosen broker, who would provide brokerage services and, in turn, negotiate with FMS the percentage of the commission FMS was to receive in cash. Any manager who failed to do sufficient business with the designated brokers was required to make up the difference through a lump-sum cash payment made directly to FMS.

The FMS arrangement placed a floor on some combination of research and portfolio trading by the managers. According to the SEC, the arrangement appeared to create a conflict of interest because it could provide an improper inducement to excessive trading by the investment manager and improperly influence the amount of commissions paid on behalf of the managed account. In spite of the purpose of the research-to identify substandard portfolio performance that could result from excessive trading by portfolio managersthe SEC found the arrangement outside the Section 28(e) safe harbor.

Because of the agency costs of professional portfolio management, managers may overuse research, pay excessively high commissions, or churn their portfolios to pay the research bill they would otherwise have to pay out of their own pockets. Jensen and Meckling (1976) placed a manager's consumption of portfolio assets in this fashion in the general category of perquisites. Because monitoring and bonding are costly, past some point, spending an additional dollar on monitoring or bonding to save 90 cents worth of perquisites will not be in the interest of portfolio beneficiaries. According to agency theory, over the long run, however, investment managers will not earn a windfall. Knowing they will be able to consume perquisites on the job in the form of free investment research, they will compete for coveted positions by offering to work for lower management fees than they would accept otherwise. Labor market competition will bid down marketwide management fees until managers' total compensation, including the value of any perquisites they consume, provides them with only a competitive wage. Competition among brokers creates the same scenario for brokerage commissions. Market competition assures that no unjust enrichment will occur over the long run. 
It would be a mistake, however, to conclude out of hand that investment managers should be left unconstrained in their use of soft dollar research simply because unjust enrichment is absent in the long run. If investment research is simply a perquisite, then providing managers with free investment research may be an inefficient form of compensation. If agency and transaction costs are sufficiently low, managers will prefer to take their compensation in the form of higher management fees and pay for investment research out of their own pockets.

Should the use of soft dollars thus be denied because it is an inefficient form of compensation? An important function of law is to reduce agency and transaction costs to eliminate socially wasteful forms of competition. The imposition of standard fiduciary duties on agents is a relevant case in point, and certainly government regulation of specific industries can effectively play a similar role. Further restrictions on or elimination of the Section 28(e) safe harbor would be ill-advised, however. Also ill-advised would be the imposition of additional mandatory disclosure regulations without considering other sources of transaction and agency costs and alternative hypotheses that explicitly take them into account. Behavior that increases the agency problem along one dimension might actually reduce aggregate agency costs across all dimensions as a whole. As Coase (1979) pointed out 20 years ago:

It is not enough to outlaw payments simply because they can be described as "improper." Some attempt should be made to discover why such payments are made and what would in fact happen in the world as it exists if they were made illegal. (p. 319)

In other words, we must base rational public policy on sound theoretical and empirical work. 


\section{The Incentive Alignment Hypothesis}

The unjust enrichment hypothesis applies to all forms of securities brokerage in which research and related products and services are bundled together with execution. The conflict of interest faced by an investment manager, therefore, arises whenever the manager pays up for bundled brokerage, whether the higher commission is designed to compensate for research supplied by outside vendors on a formally metered basis or for proprietary research conclusions supplied on an informal basis by the research departments of brokerage houses. Soft dollars are simply one method of bundling research and execution together into a single commission payment. ${ }^{6}$

None of the common criticisms of soft dollars focuses on what is unique about them. Soft dollars are unique in that they formally account for the research subsidy, they allow research and execution to be supplied by separate firms, and they allow the research subsidy and the associated executions to occur at different times. In short, soft dollars are heavily criticized for formally accounting for what is largely hidden in the full-service brokerage setting, and an understanding of their welfare effects requires a more careful analysis of the incentives they create than prior commentators have recognized.

In this chapter, we introduce an alternative to the unjust enrichment hypothesis to account for the persistence of soft dollar use. According to the incentive alignment hypothesis, soft dollars reduce agency and transaction costs by aligning managers' and brokers' interests with those of portfolio beneficiaries.

For most active managers, the annual management advisory fee is a recurring 50-100 basis points of net asset value. Although this arrangement makes them partial owners of the portfolio, their ownership share is substantially less than 100 percent, which leads to a divergence of interests between managers and portfolio beneficiaries. The incentive alignment hypothesis provides a framework for understanding how the parties organize their relationships to reduce agency and transaction costs and minimize the associated losses. Our analysis recognizes that both managers and brokers are agents of portfolio beneficiaries.

\footnotetext{
${ }^{6}$ Recognizing in-house and third-party research as identical in terms of bundling is consistent with AIMR disclosure standards (see AIMR Soft Dollar Standards 1998, p. 4).
} 
One implication of agency theory is that because managers bear less than 100 percent of the benefits they generate for their portfolios, they may do a careless job of monitoring the securities trades of executing brokers. We demonstrate that soft dollars provide a solution to this potential problem by bonding the quality of brokers' executions.

A second implication of agency theory is that if investment managers were required to pay for all research and execution out of their own pockets, they would do too little research, identify too few profitable trading opportunities, and perform too few portfolio trades. Again, we demonstrate that soft dollars provide a solution to the problem, in this case by subsidizing investment research.

\section{Aligning Broker Incentives with Beneficiaries' Interests}

When an investment manager is able to identify mispriced securities, profitable trading on behalf of the portfolio requires the manager to monitor brokers to ensure that they provide the best execution possible by minimizing the price impact that occurs as a result of leakage. A broker might shirk his obligations by searching carelessly for better prices or inadvertently leaking the news of impending trades to interlopers. He might also consume perquisites by front-running the manager's trades or by purposely leaking the news to an associate. Because of the inherent noisiness of security prices, however, execution quality is difficult to assess in the short run. The problem is especially severe for managers who are well informed. For them, identifying mispriced securities may be the easy part; the difficult part is getting the trade executed discretely with minimum price impact in a market filled with potential interlopers.

The necessity to monitor brokers' execution quality illustrates the multiple-agency problem that arises in the context of delegated portfolio management. Like the manager, the broker is an agent of the portfolio. Even if the manager could capture all the benefits from monitoring the broker's execution quality (when, for example, the manager owns 100 percent of the portfolio), the manager would suffer a residual wealth loss because monitoring execution quality is costly. For a sole principal to monitor perfectly simply does not pay. A manager who owns only a small percentage of the portfolio and receives only a fraction of the gains from monitoring the quality of the broker's executions will tend to do little monitoring, so leakage and price impact are more likely to occur in this case.

The evidence indicates that price impact accounts for as much as 80 percent of execution costs, that it can have a large long-run effect on portfolio performance, and that it is at least partly caused by leakage. For example, 
several well-known empirical studies have shown that certain investment managers routinely pay higher-than-average brokerage commissions and incur higher-than-average market impact costs on their trades (Berkowitz, Logue, and Noser 1988; Chan and Lakonishok 1993). The superficial inference from this observation is that these managers are lazy or incompetent. But such a situation would not persist. A more plausible inference is that some managers are, at least temporarily, reputed to have superior information and frequently lose some of the information's value to interlopers through leakage when they enter the market to trade. To minimize the problem, they must pay their brokers a commission premium to execute trades. At the margin, however, they will rationally tolerate some amount of price impact rather than paying up completely. To the extent that they are successful in effectively using brokers to reduce leakage, they should reap excess portfolio returns.

The importance many brokers place on order flow reveals the prevalence of the leakage problem: Brokers who traded exclusively on behalf of those with superior information would face the same leakage problem as the clients the brokers represent. No one would trade with them except at a price that reflected the clients' superior information. This scenario accounts for the willingness of many broker/dealers to pay a cash rebate for retail order flow. Only by regularly performing a large number of routine, uninformed trades can a broker hope to disguise the informed trades and preserve the informed clients' anonymity. The tendency we have noted of investment managers to engage in what appears to be uninformed noise trading may stem from the same reasons. By routinely making trades they know to be uninformed, managers who occasionally have private information about mispriced securities can effectively obscure their informed trades and limit the leakage that leads to price impact.

Execution quality that minimizes price impact is impossible to measure in the short run. So, how do the parties overcome the problem? Their approach can be understood by reference to a well-known economic model of how premium prices (paying up) can assure high-quality performance. In Klein and Leffler's (1981) simple model, the producer has the choice of supplying either a high-quality good or a low-quality good. Of course, the high-quality good is more costly to produce than the low-quality good, but consumers are willing to pay a higher price for it. If consumers offer to pay only a price equal to the production cost for either good, the producer is indifferent between supplying the high- and low-quality goods because in either case, the producer just barely covers costs, including a normal operating profit. Because it takes consumers time to differentiate high from low 
quality, they assume when they go to purchase the products that the producer will supply the low-quality good even when claiming to be supplying the high-quality good. Thus, they are unwilling to pay more than the low-quality price. The low-quality good drives out the high-quality good, which produces the so-called lemons problem.

To avoid the lemons problem and assure that the producer supplies the high-quality good, the parties can organize their transaction in the following way: Consumers offer to pay the producer a unit price premium above the cost of supplying the high-quality good if the producer promises not to cheat them by deceptively lowering quality. The quality-assuring premium must be sufficiently high that its net present value (appropriately weighted by sales in each of an indefinite number of periods) exceeds the one-time gain to the producer from cheating. The one-time gain from cheating equals one-period sales times the difference between the premium price (which consumers pay thinking that they are getting the high-quality good) and the cost of producing the low-quality good (which is what the producer actually supplies if the producer decides to cheat). The length of one period is defined by the time it takes consumers to determine that they have been cheated, after which they refuse to pay any price greater than the low-quality price. Under these circumstances, by construction, the producer finds that maintaining high quality is more profitable than cheating.

This method of avoiding the lemons problem allows the producer to earn a surplus above the normal operating profit, but the outcome cannot persist for long. Competition among producers to capture the surplus would ordinarily lead to price cutting, but price cutting destroys the quality-assuring equilibrium, and the lemons problem reappears. So, a producer must rely on some method other than price competition to vie for consumers' favor.

The method that works is for the producer to make a sunk capital investment, for the benefit of consumers, the cost of which is equal to the present value of surplus profits. According to this calculus, the producer is indifferent between supplying the high- or low-quality good at the outset. But if the producer chooses to supply the high-quality good and makes a capital investment for the benefit of consumers, the producer is locked into providing the high-quality good. The reason is that the capital investment is sunk, so the producer cannot salvage it by deciding to lower quality. The only way the producer can earn a normal return on the capital investment (i.e., continue to earn a price premium) is to continue supplying the high-quality product. Thus, the capital investment serves as a kind of "reputational performance bond" signaling consumers that the producer has more to gain by providing the high-quality good than by cheating. Consumers respond by trusting the producer and making repeat purchases of the producer's product. 
Note that competition will lead the producer to choose, from among all the possible sunk capital investments, the form of investment that has the highest possible value to consumers. In consumer goods markets, the producer's sunk investment often takes the form of tangible or intangible capital associated with its brand name. Product advertising and costly celebrity endorsements are common examples. In fast food and gasoline retailing, the standard examples are signs and globes bearing company logos that allow motorists to identify them easily from a distance. Such signs and globes are entirely specific to the company in question and would have little or no value if the company were to cease operations.

This model closely reflects the circumstances facing investment managers and their brokers. Discount brokerage, which costs about 2 cents a share, can be considered the low-quality product. ${ }^{7}$ Careful execution of difficult trades with a minimum of price impact, which runs 6 cents a share or more, can be seen as the high-quality good. But price impact, and thus execution quality, is impossible for the manager to assess in the short run; deviations from the expected outcome are difficult to identify because of the inherent noisiness of security prices. Only over the long course of a trading relationship can the manager realistically hope to make an accurate assessment of the quality of a broker's executions. In that span of time, low-quality brokerage can have a substantial negative effect on the manager's performance.

When a manager agrees to pay up for soft dollar brokerage, the broker earns a commission premium for performing high-quality trades in exchange for an up-front research subsidy. The research subsidy constitutes a capital investment made by the broker for the benefit of the investment manager and is roughly equal to the present value of the broker's expected commission premiums. ${ }^{8}$ If the broker cheats by front-running or by providing low-quality executions, the broker risks being discovered and having the contract terminated with the account balance unpaid. Because the broker typically provides the research subsidy to the manager up front, the manager's account debit

\footnotetext{
${ }^{7}$ Discount brokerage is not inherently low quality. For the many investors whose trades are uninformed, such as those trading for liquidity reasons, discount brokerage is surely adequate. For institutions, which often trade in large blocks and whose trades are often presumed to be motivated by private information, discount brokerage is surely inadequate and can be accurately described as the low-quality good.

${ }^{8}$ If the average institutional commission is 7 cents a share, 3 cents of which goes to pay for the manager's research, then the cost of performing high-quality executions is about 4 cents a share, 2 cents more than the cost of discount brokerage. The premium in this case is the difference between the actual commission and the cost of performing high-quality executions, or 3 cents a share.
} 
with the broker bonds the quality of the broker's performance. ${ }^{9}$ Note that this bond is entirely sunk and, therefore, completely specific to the continued provision of high-quality executions. Part of the reason is the SEC's ruling that to be under a legal obligation to perform promised trades risks the loss of Section 28(e) protection. Although stories of outright reneging on a promise to pay for trades by portfolio managers are uncommon, they have indeed appeared in the financial press from time to time, and in one reported case, a soft dollar broker became insolvent as a result. Moreover, a manager can implicitly renege by sending the broker a large number of easy trades and refusing to pay anything but the low-quality commission rate, thereby stripping the broker of expected commission premiums.

The only remaining question with regard to the role soft dollar brokerage plays as a method of assuring high-quality brokerage is why an up-front research subsidy paid by the broker to the manager is the form of sunk capital investment that provides the maximum value to the portfolio. To answer this question, we need to examine the nature of the agency problem in professional portfolio management. Recall that if investment managers were required to pay for all research and execution out of their own pockets, they would bear a disproportionate share of the costs of generating portfolio returns in relation to the private benefits based on their ownership share. They would tend to do too little research, identify too few profitable trading opportunities, and perform too few portfolio trades. By bundling the costs of research and execution into a single trading commission paid by portfolio beneficiaries, soft dollars not only increase the manager's incentive to trade, but they also provide the manager with the research necessary to identify profitable trades. Therefore, by aligning managers' interests with those of portfolio beneficiaries, an upfront research subsidy probably constitutes the most valuable sunk capital investment the broker can provide on behalf of the portfolio.

\section{Aligning Manager Incentives with Beneficiaries' Interests}

To accurately assess the welfare effects of soft dollar brokerage, we must take into account the agency problem along all dimensions of investment management. The unjust enrichment hypothesis holds that soft dollars allow investment managers to engage in perquisite consumption at the expense of

\footnotetext{
${ }^{9}$ One soft dollar broker confided that his soft dollar "accounts receivable" at any moment amount to about $\$ 6$ million, as compared with a total capitalization of $\$ 20$ million to $\$ 30$ million. On Wall Street, where news notoriously travels fast and a person's reputation is his or her stock in trade, a soft dollar broker who clearly cheats one client by, say, front-running might well be terminated by a large number of other clients. The deterrent effect of prospective termination on the diligence with which soft dollar brokers execute trades thus appears to be substantial.
} 
portfolio beneficiaries. But a second broad category of agency costs results from shirking by agents, who will tend to do too little of activities that benefit the principal if they are required to bear 100 percent of the costs. As with an agent's consumption of perquisites, monitoring by the principal and bonding by the agent give the agent an incentive to perform on behalf of the principal. Some shirking will be inevitable, however, and some residual loss will persist.

The residual loss provides the parties with opportunity to increase their joint wealth by developing solutions to the shirking problem. One obvious solution that is popular in many agency settings is for the principal to compensate the agent based on performance rather than on an hourly wage or a monthly salary. With performance-based compensation, the agent's wealth rises and falls with the principal's wealth, even though the association is imperfect.

Another method to reduce shirking that is used almost universally in the principal-agent setting is for the principal to subsidize the agent's use of productive inputs. Portfolio beneficiaries hire active investment managers as agents to identify and implement trades that are expected to increase portfolio wealth. Assuming, for simplicity, that capital contributions are a fixed factor input, "management" can be seen as the variable factor input in the production of portfolio returns. In the soft dollar setting, management is actually a composite input consisting of the optimal combination of three complementary factors: investment research in the form of third-party products and services, the manager's diligent labor, and high-quality brokerage executions. The more factors of given quality the manager devotes to the portfolio over the relevant range, the greater the expected portfolio wealth. But this process is subject to the economic law of diminishing marginal returns: All else being equal, additional inputs yield successively smaller expected wealth increments (expected returns to the portfolio). This situation is illustrated in Figure 1, where the $M W$ curve provides a simple representation of the expected marginal wealth increment to the portfolio from additional management inputs per period, $I$, when the manager bears all the costs of research.

To understand the agency problem in investment management, and the resource misallocation it engenders, we must identify the marginal cost of management inputs. This knowledge will allow us to determine the optimal level of inputs from the parties' joint viewpoint. We designate the marginal cost $M C_{R+L+E}$, which reflects the marginal cost of management inputs when research, labor, and execution are combined in efficient proportions in the production of portfolio wealth. In these circumstances, the optimal level of management inputs from the parties' joint viewpoint occurs at $I^{\star}$ in Figure 1, 


\section{Figure 1. Marginal Wealth, Marginal Cost, and Inputs When the Manager Bears All Costs}

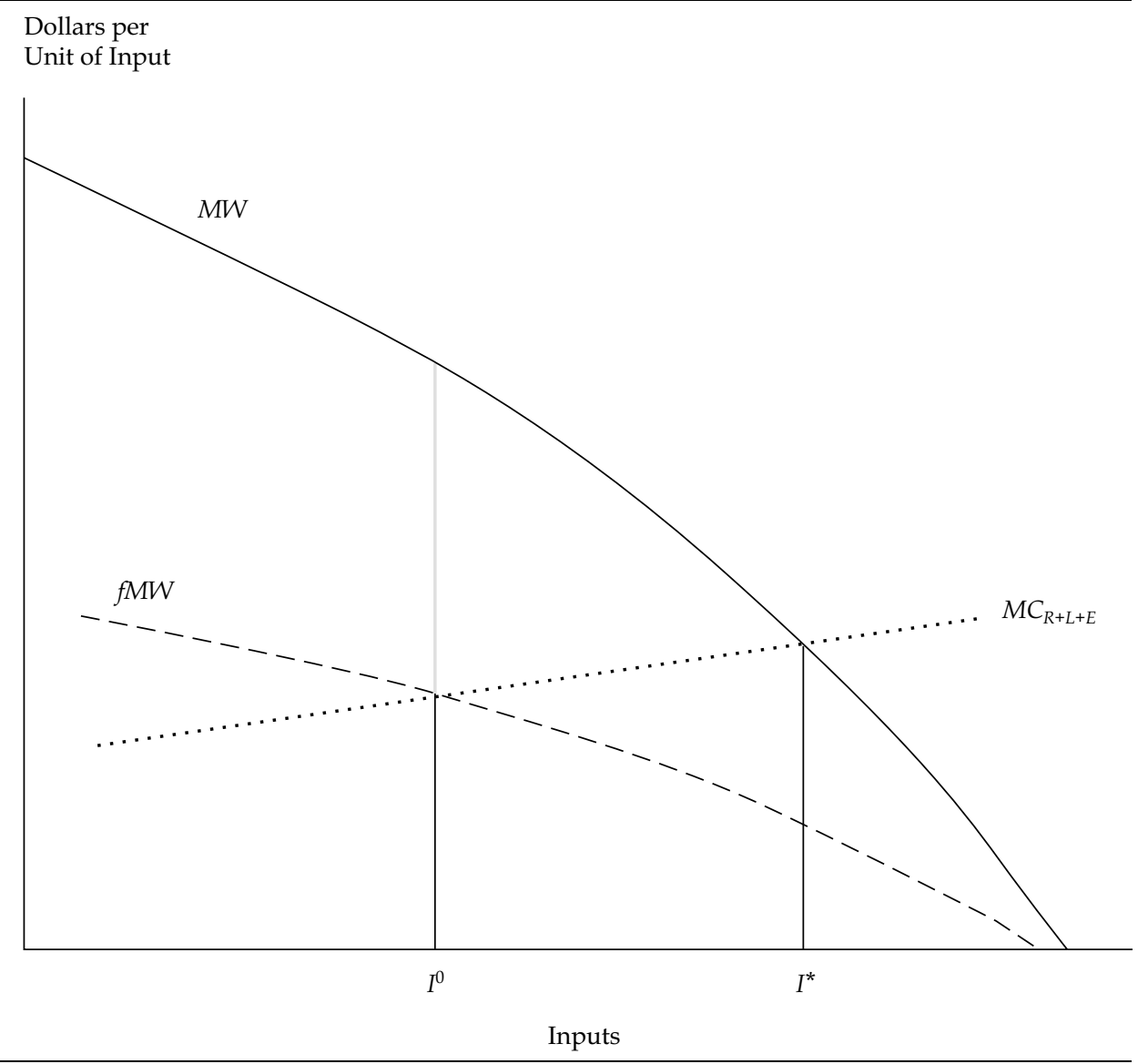

Note: For simplicity, the parties are assumed to be risk neutral and a dollar in expected wealth is assumed to have the same value as its certainty equivalent.

precisely where the $M C_{R+L+E}$ curve intersects the $M W$ curve and where an additional dollar's worth of inputs yields exactly a dollar in expected wealth. Any deviation from $I^{\star}$ will reduce portfolio performance and the parties' joint wealth. The problem the parties seek to solve in their choice of economic organization is how to provide the manager with the incentive to bring the chosen level of management inputs as close to $I^{\star}$ as is economically feasible.

The shirking problem can be illustrated by considering how investment managers are compensated and the extent to which they bear the costs of management inputs. Most portfolios pay their managers a recurring share of 
portfolio wealth (net asset value), with the periodic sharing percentage typically in the range of 50 to 100 basis points. With the manager's fractional share of portfolio wealth increments designated as $f$, the curve $f M W$ in Figure 1 represents the marginal wealth increment received by the manager from devoting additional inputs to the portfolio. ${ }^{10}$ If the manager is required by the terms of the advisory contract to bear all the costs of management inputs, the manager will tend to shirk by using too few inputs. Rather than $I^{\star}$, the manager may choose what is indicated on Figure 1 as $I^{0}$ inputs, where the $f M W$ curve, which reflects the manager's private benefits from providing management inputs, intersects the $M C_{R+L+E}$ curve.

Note that at $I^{0}$, the marginal wealth increment to the portfolio from additional management inputs is substantially greater than the marginal input cost. This difference, summed from $I^{0}$ to $I^{\star}$, illustrates the loss in wealth that the parties experience because of shirking by the manager. It also represents the parties' potential wealth gain from developing further solutions to the shirking problem.

One solution is for portfolio beneficiaries to take an active role in monitoring the manager's use of inputs. Effective monitoring is next to impossible, however, in many portfolios, such as mutual funds. Even when the portfolio is managed on behalf of a single client, monitoring will be imperfect.

Fortunately, other solutions to the shirking problem are possible. The most obvious solution, and the one that occurs to some extent in many agency settings, is for the principal to subsidize the cost of those inputs specifically devoted to enhancing portfolio wealth by allowing them to be charged to the portfolio. Because the manager shares $f$ of portfolio wealth, the manager also bears $f$ of the cost of the subsidy. An ideal subsidy would give the manager an equal share of all the costs and benefits of operating the portfolio. Such a

\footnotetext{
${ }^{10}$ In most cases, the manager's effective share of portfolio wealth will exceed the periodic share. Assuming a 50 basis point advisory fee, if the manager generates an increase in fund wealth of $\$ 100$ in Year 1 , the manager's share is 50 cents. If this wealth increase persists, which given efficient asset pricing it will be expected to do, the manager will receive an additional 50 cents in Year 2, and so forth. In the limiting case in which the wealth increase is permanent, the manager is expected to live forever, and the manager is expected to hold her position indefinitely, the manager's marginal wealth gain will equal the discounted present value of a 50 cent perpetuity. At an interest rate of 10 percent, this perpetuity is worth $\$ 5$, or 5 percent of NAV. What is more, successful managers, whether they are engaged in mutual fund management or private portfolio management, will attract additional investment dollars from their clients. Appendix A shows how a mutual fund manager's share is determined when superior performance in one period affects fund inflows in subsequent periods. Under plausible assumptions, the mutual fund manager's effective share of portfolio wealth is close to 17 percent of incremental portfolio wealth. No doubt, successful private investment managers experience similar inflows of investment dollars or renegotiate higher fees.
} 
subsidy would lead the manager naturally to choose $I^{\star}$ inputs. This compensation scheme is impossible to achieve in practice because the real opportunity cost of the manager's labor effort is impossible to know, which leaves the parties with no choice but to seek a second-best solution.

It is no accident that, as a matter of long-standing convention, most portfolios explicitly bear the cost of portfolio executions by including brokerage commissions in the price basis of portfolio securities. Assuming this subsidy is confined to pure execution (with zero bundled research), its effect is to reduce the out-of-pocket costs of the manager from providing management inputs. Figure 2 shows how the costs shift down from $M C_{R+L+E}$ to $M C_{R+L}$. At the same time, the cost of pure execution is charged to the portfolio, which has

\section{Figure 2. Marginal Wealth, Marginal Cost, and Inputs When the Portfolio Pays Pure Execution Costs}

Dollars per

Unit of Input

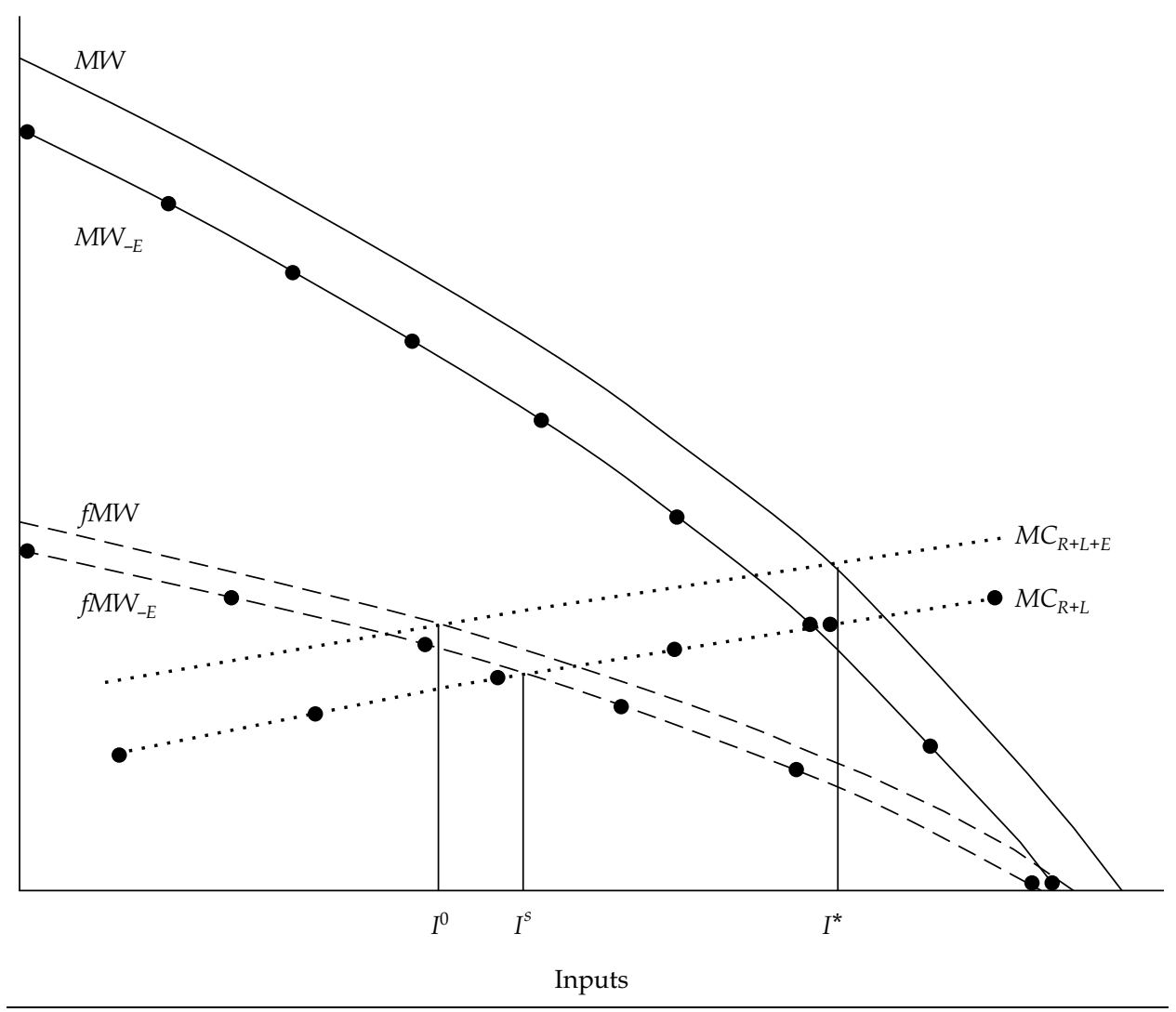


the effect of shifting the $M W$ curve down vertically by exactly the same distance, to $M W_{-E}$. Because the manager receives an $f$ share of portfolio wealth, the manager now perceives his private benefits from providing management inputs to be $f M W_{-E}$. The manager bears only a fraction, $f$, of the cost of portfolio execution. The manager will tend to choose the level of management inputs that equates his private benefits, represented by $f M W_{-E}$, with his private costs, represented by $M C_{R+L}$. This level occurs at $I^{S}$, which necessarily lies to the right of $I^{0}$, closer to the optimal choice of inputs, $I^{\star}$. The residual loss resulting from shirking thus will be reduced but not eliminated by the pure execution subsidy, and the parties' joint wealth will increase.

This solution poses several problems. First, to the extent managers can convert subsidized portfolio executions into personal wealth, the perquisite problem again arises. Such conversion by managers falls outside the Section 28(e) safe harbor, however, and has little to do with the issues addressed here. Second, to the extent that pure portfolio executions are a viable substitute for either investment research or managerial labor, managers will have an incentive to use the inputs in suboptimal combinations. They will tend to conserve on investment research and their own labor, which they pay for out of their own pockets, and treat portfolio executions as a free good in an attempt to gain personal advantage. Little evidence on the subject exists, but we find it difficult to imagine how uninformed and essentially random trading could possibly allow the manager to gain a purely private advantage. ${ }^{11}$ Moreover, to the extent that this activity is widespread, over the long-run, management fees will adjust to mitigate the effect. In any event, subsidizing portfolio executions is advantageous for portfolio beneficiaries as long as $M C_{R+L}$ lies below $M C_{R+L+E}$. In such circumstances, the total level of inputs chosen by the manager will be closer to $I^{\star}$ and the wealth loss will be smaller.

As long as $I^{S}$ lies to the left of $I^{\star}$, portfolio beneficiaries may be able to further reduce the shirking problem by subsidizing both portfolio executions and investment research. If the manager is able to convert the research subsidy into personal wealth, however, the advantages of such a subsidy are limited. As in any agency setting, this outcome occurs from time to time in investment management, but it does not appear to be a widespread problem. ${ }^{12}$

\footnotetext{
${ }^{11}$ According to our analysis, for the manager to engage in a certain amount of uninformed noise trading to obscure the trades that are motivated by private information is in the interest of the portfolio.

${ }^{12}$ The SEC's Inspection Report provides specific examples, most of which occurred in a private money management setting, where the client can effectively contract with and monitor the investment manager, rather than in the public investment company setting, where portfolio beneficiaries are numerous and dispersed.
} 
One way for the portfolio to subsidize investment research is to allow the manager to buy both research and execution with a single premium brokerage commission paid by the portfolio. Assuming the manager continues to combine research, labor, and execution in an optimal combination, this subsidy will shift the private cost of management inputs down to $M C_{L}$ as shown in Figure 3; at the same time, it will shift the return from management inputs down from $M W_{-E}$ to $M W_{-E-R}$. As before, the manager will increase the level of management inputs, this time to $I^{s s}$, where $M C_{L}$ intersects $f M W_{-E-R}$. The

\section{Figure 3. Marginal Wealth, Marginal Cost, and Inputs When the} Portfolio Pays Bundled Execution and Research Costs

Dollars per

Unit of Input

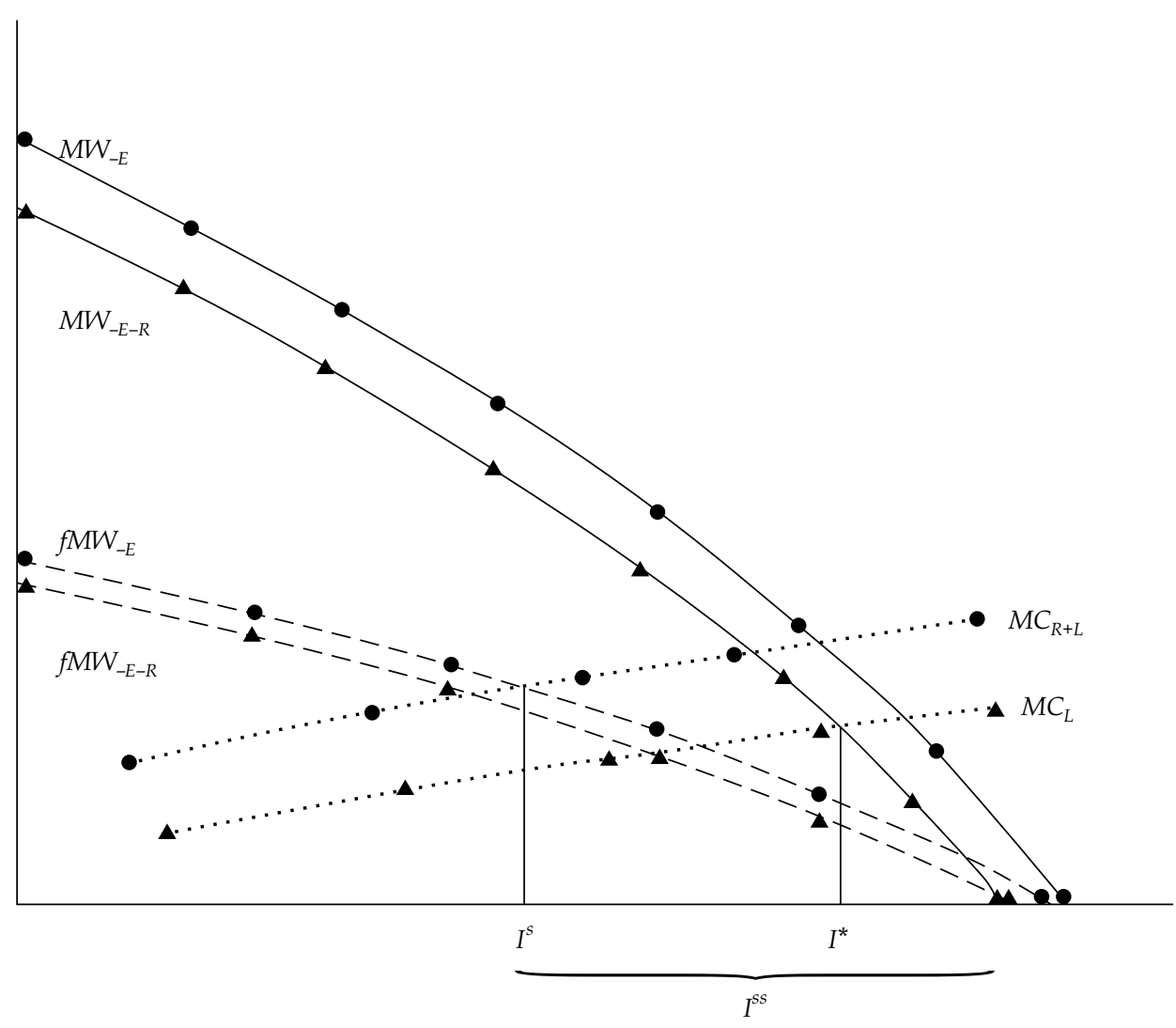


managerial input $I^{S S}$ necessarily lies somewhere in the range to the right of $I^{S}$ in Figure 2, quite possibly bringing the parties closer to $I^{\star}$ than before.

But $I^{S S}$ could lie to the right of $I^{\star}$; that is, the subsidy could actually lead the manager to provide too many management inputs compared with what would maximize the parties' joint wealth. Unlike the situation in which the portfolio subsidizes only pure execution, it is easy to imagine how the manager could gain by substituting unlimited research and portfolio executions for the manager's own labor. The manager will tend to treat both execution and investment research as free goods and overuse them to conserve on labor. The reason is that by paying up for full-service brokerage, the manager can, in essence, buy proprietary research conclusions generated by the broker's labor rather than the manager's. If the manager can purchase only nonconclusory third-party research inputs (that is, inputs but no conclusions or recommendations) with bundled brokerage, as appears to be the case with soft dollars, the manager has little to gain from suboptimal substitution because she must also contribute her own effort to discover the private information that makes the trades that generate the subsidy worth executing in the first place. Thus, the bundled research provided by full-service brokers, which tends to be proprietary and conclusory, may be especially troublesome from an agency standpoint. It allows managers to substitute bundled brokerage for their own labor. In theory, by paying up sufficiently for full-service brokerage, managers can reduce their own effort in identifying profitable trades to zero. 13

One way to prevent suboptimal substitution is to tie research and execution together in fixed proportions so that the manager can increase use of one only by increasing use of the other. Bundled brokerage in the form of soft dollars, where the ratio of investment research costs to execution costs is set in a competitive marketplace, is likely to achieve the optimal result. The reason is that the transacting parties will choose the form of economic organization that takes advantage of every opportunity for mutual gain, subject only to the limitations imposed by transaction costs. Even though managers have an incentive to substitute bundled brokerage for their own labor, soft dollar brokerage requires them to use research and execution in fixed proportions; research and execution cannot be substituted one for the other. If research and execution are joint complements to the manager's labor, subsidizing research and execution will increase the manager's effort and total management inputs.

\footnotetext{
${ }^{13}$ As noted previously, this outcome suffers from the favoritism problem; that is, full-service brokerage houses would prefer to give superior access to this research to their in-house money managers. Favoritism would dramatically reduce the net returns from buying proprietary research.
} 
Why not simply have the broker make the advance rebate to the portfolio in the form of cash? Such a move would ensure that the portfolio would receive something of value equal to what it pays out in premium commission and at the same time provide an effective performance bond. The problem with this solution is that any manager who intends to actively engage in investment research to identify mispriced securities will find research products more productive than cash. The broker will prefer to patronize such managers because they are far more likely to generate the informed trades that give rise to premium commissions than a manager who asks the broker to deposit cash into the portfolio, at least if research is a complement to the manager's labor in identifying mispriced securities. In essence, by taking rebates in research products rather than cash, managers credibly signal that they are likely to fulfill their trading obligations with a broker.

When the parties enter into a soft dollar arrangement, they envision a brokerage commission rate that is based on an average of their expectations. Thereafter, difficult trades and easy trades may be pooled together at the average rate. In some cases, the portfolio manager actually determines the brokerage commission rate on each trade after it is completed; in these cases, difficult and easy trades are surely pooled from the broker's viewpoint. ${ }^{14}$ The rate will depend on the manager's ex ante assessment of trade difficulty, ex post assessment of the broker's performance, and the nature of the manager's relationship with the broker. The broker prefers a higher commission rate, of course, because it decreases the manager's account balance more quickly than a lower rate. In either case, all trades are average-priced from the broker's perspective, which leaves the broker with a pool of the high-cost difficult trades and the low-cost easy trades. This pooling raises the cost to interlopers of identifying informed trades and reduces the likelihood of a price impact on trades. Moreover, as long as the manager intends to fulfill her trading obligation with the broker over the established term of the soft dollar arrangement, this system can be used to reduce the manager's marginal cost of trading almost to zero. By agreeing to a sufficiently large trading obligation, the manager reduces her marginal cost of engaging in noise trading to obscure informed trades. Again, this outcome tends to raise the cost to interlopers of identifying informed trades and reduces the likelihood of a price impact.

\footnotetext{
${ }^{14}$ In fact, the broker may not know until after the trade is completed whether the commission will be a soft dollar commission or a hard dollar commission. Our information comes from an informal survey of institutional brokers. Obviously, such business dealings require the broker and the manager to trust one another.
} 
According to accepted agency theory, portfolio managers have insufficient incentive to identify profitable portfolio trades. This section has shown how bundling might reduce the shirking problem with respect to one dimension of investment management. By subsidizing both portfolio executions and investment research and by tying them together in a fixed ratio (at least in the case of soft dollars), bundling appears to align managers' incentives with the interests of portfolio beneficiaries. Seen in this light, Logue's (1991) assertion that soft dollar research does not pass a cost-benefit test is suspect. Burgunder and Hartmann's (1986) assertion that in the absence of Section 28(e) protection managers would continue purchasing research "until the last hard dollar spent for the research equaled the value of that research to the clients" is simply wrong. So, too, is the conclusion that soft dollars necessarily lead managers to purchase too much research. Although these commentators implicitly rely on the agency problem to infer that investment managers might have misaligned incentives, by failing to look carefully at the parties' choice of economic organization, they draw exactly the opposite conclusion from what standard agency theory would suggest in the circumstances.

The SEC's concern about the Fund Monitoring Services' arrangement (that the floor placed on some combination of research and brokerage by the managers "could provide an improper inducement to excessive trading") is similarly misplaced. Although the FMS arrangement may have led to increased trading by the managers, the increased trading was not necessarily excessive according to the incentive alignment hypothesis. In fact, given that the FMS arrangement was administered by the central advisor of the fund complex, whose function was to monitor manager performance, it seems extremely unlikely that the arrangement would have led to excessive trading and reduced portfolio performance.

By carefully examining soft dollars as an efficient form of economic organization, we have made in this chapter an entirely plausible case that they actually reduce the agency and transaction costs of professional portfolio management by properly aligning the parties' incentives. Soft dollars appear to bond the quality of brokerage executions and to encourage managers to identify profitable portfolio trades. Any rebate the broker provides that subsidizes complementary inputs into the investment research process is likely to qualify as the most valuable capital investment the broker can make on behalf of the portfolio. Of course, as noted previously, soft dollars could lead a manager to carry out too much research, thereby reducing investor welfare. The only scientific way to differentiate two such plausible but conflicting hypotheses is to compare their empirical predictions with what is actually found in the real world. 


\section{Tests and Findings}

In this chapter, we identify testable implications for the unjust enrichment hypothesis and the incentive alignment hypothesis, describe the data we used and tests we performed, and present our findings.

\section{Testable Implications}

Both the incentive alignment hypothesis and the unjust enrichment hypothesis predict that soft dollars will lead managers to use more research and to trade more often than otherwise. According to the incentive alignment hypothesis, this effect increases the parties' joint wealth by reducing agency and transaction costs and moving the manager toward optimality. According to the unjust enrichment hypothesis, soft dollars lead managers to pay excessively high commission rates, to overuse research, and to engage in excessive portfolio turnover, which leads to a wealth transfer from portfolio beneficiaries to managers.

The observed relationship between soft dollar use and commission rates cannot be used to distinguish between the two hypotheses because both predict the manager will pay higher rates. The incentive alignment hypothesis views higher commissions as necessary to provide a quality-assuring brokerage premium and to compensate for an efficient research subsidy. The unjust enrichment hypothesis makes the same prediction but contends that the soft dollar rate exceeds the value of research and high-quality brokerage combined. For example, both hypotheses predict that commission rates for index funds, which have little or no reason to pay up for high-quality brokerage or for research, should be lower than commission rates for actively managed funds.

Comparing soft dollar use in situations characterized by high and low agency costs also generally fails to distinguish the two hypotheses. The incentive alignment hypothesis predicts soft dollar use will be greater when agency costs are high because soft dollars help to align managers' incentives when alternative monitoring or bonding mechanisms are uneconomical. The unjust enrichment hypothesis also predicts soft dollar use will be greater when agency costs are high because the high monitoring costs faced by portfolio beneficiaries enable managers to use soft dollars to unjustly enrich themselves.

One proxy for cross-sectional differences in agency costs is ownership concentration. When ownership is concentrated in the hands of relatively few owners, the collective action problem between co-owners is limited. In the 
context of private portfolio management, money managers may handle anywhere from a single account to tens of thousands of accounts. With each account normally associated with a different client, having fewer accounts under management (i.e., higher ownership concentration) should be associated, all else being equal, with better monitoring. Both hypotheses, therefore, predict that managers with highly concentrated account bases will, all else being equal, engage in less paying up for soft dollars.

The most obvious way to determine the effect of soft dollars on the welfare of portfolio beneficiaries is to examine how risk-adjusted returns vary with the extent to which managers pay up for bundled brokerage. The incentive alignment hypothesis predicts that soft dollars will lead to higher risk-adjusted returns by allowing managers to effectively bond the quality of brokerage executions and by encouraging managers to perform more investment research. The unjust enrichment hypothesis predicts that soft dollars will lead to lower risk-adjusted returns as a result of manager self-dealing. The test of this implication is one of the most compelling we present.

Another way to distinguish between the incentive alignment hypothesis and the unjust enrichment hypothesis is to examine the effect soft dollars have on management fees. If managers use soft dollars to unjustly enrich themselves, part of the residual loss will be reflected in the managers' market wages. The reason is that managers will anticipate the opportunity to convert portfolio assets to their own use and will compete for the opportunity by offering to work for lower fees. For example, large pension funds are surely in a position to have exclusive contracts with investment managers and to prohibit them from using soft dollars. To induce a manager to accept such a contractual restriction, a pension fund will need to pay higher management fees than clients who do not insist on such terms. If soft dollars are an effective incentive alignment mechanism when other mechanisms fail, then management fees should be unrelated (or perhaps even positively related) to soft dollar use.

\section{The Data}

Our data were supplied by Mobius Group, which has been in the business of selling investment manager returns data to the public since 1989. The database fairly represents pension assets and institutional money management generally. For example, the pension assets in our database represented 54 percent of all pension assets in the United States as reported in the Federal Reserve Board's "Flow of Funds" report for 1993. Furthermore, our database included 940 of the largest 1,000 tax-exempt money managers as reported by Pensions \& Investments (Schramm 1994, p. 2-4). Tax-exempt 
assets composed 84 percent of the equity assets in our database, and according to the Federal Reserve Board, 83 percent of all institutional equity holdings are tax exempt. ${ }^{15}$

Because our database covered institutional rather than retail managers, it contained large institutional index managers but not popular retail index fund managers. Approximately 14 percent of the equity assets in the sample were indexed, and Pensions \& Investments reports that 13 percent of total pension assets were indexed in 1993 (Schramm 1994, p. 2-4). Table 1 provides descriptive statistics for the 1,273 U.S. equity portfolios in our database.

Managers in our study could report returns for multiple portfolios, each with its own management style. Consequently, the database included both firm-level and portfolio level data. Because returns, commission rates, turnover, and management fees are reported at the portfolio level, our unit of study was the portfolio rather than the advisory firm. Each portfolio represented any number of different accounts, and each account was normally associated with a different client. Although the data were retrieved from the fourth quarter 1994 database, we report data from fourth quarter 1993 because many managers take several quarters to update their reports. Panels $\mathrm{A}$ and $\mathrm{B}$ of Table 1 show the number of accounts managed in each portfolio and the distribution of portfolio assets. The standard deviations are large, and the distributions are skewed. Not only is the median portfolio below the mean in size, but the portfolio in the 75th percentile is also below the mean. ${ }^{16}$

An issue worth addressing in regard to our data is how the accuracy of investment manager return data for private portfolios compares with that for mutual funds. The SEC plays an active role in monitoring the reporting of mutual fund returns, which may improve the quality of mutual fund reporting over the reporting of returns for private portfolios; the monitoring costs for dispersed mutual fund investors are likely to far exceed the private benefits. The money management industry has alternative monitoring mechanisms, however, because the net benefit from monitoring money managers is probably fairly high for many pension plan sponsors. Perhaps this benefit explains why the industry of pension fund consultants has emerged to screen the data and weed out high-quality from low-quality money managers.

\footnotetext{
${ }^{15}$ We used tax-exempt assets as a proxy for pension assets because pension funds are the most common tax-exempt vehicle and common industry practice is to use the two sets of assets synonymously.

${ }^{16}$ In the statistical tests, we transformed portfolio assets and the number of accounts managed by use of a natural log operator so that the distributions would be closer to normal. We calculated Shapiro-Wilk test statistics for normalcy by the method presented in Shapiro and Wilk (1965). Distributions whose Shapiro-Wilk test statistics differ insignificantly from 1 are considered to be normal.
} 
Table 1. Descriptive Statistics for Money Managers in the Study, as of 1993

\begin{tabular}{|c|c|c|c|c|c|c|c|c|c|}
\hline \multirow[b]{2}{*}{ Characteristic } & \multirow[b]{2}{*}{ Mean } & \multicolumn{5}{|c|}{ Percentile } & \multicolumn{3}{|c|}{ Shapiro-Wilk } \\
\hline & & Minimum & $25 \%$ & Median & $75 \%$ & Maximum & Deviation & $(\operatorname{Pr}<W)^{a}$ & $N$ \\
\hline \multicolumn{10}{|l|}{ A. Number of accounts managed } \\
\hline Tax exempt & 71.4 & 0 & 3 & 11 & 30 & 16,436 & 701.6 & $0.08(0.00)$ & 1,091 \\
\hline Taxable & 120.0 & 0 & 0 & 3 & 26 & 44,530 & $1,698.7$ & $0.06(0.00)$ & 1,086 \\
\hline Total & 190.9 & 1 & 5 & 16 & 62 & 60,966 & $2,363.6$ & $0.07(0.00)$ & 1,120 \\
\hline $\ln ($ Total) & 2.88 & 0 & 1.6 & 2.8 & 4.1 & 11.0 & 1.8 & $0.96(0.00)$ & 1,120 \\
\hline \multicolumn{10}{|l|}{ B. Portfolio assets ( $\$$ millions) } \\
\hline Tax exempt & 747.4 & 0 & 23 & 123 & 526 & 30,495 & 2,201 & $0.35(0.00)$ & 1,098 \\
\hline Taxable & 143.2 & 0 & 0 & 17 & 93 & 5,222 & 448.2 & $0.34(0.00)$ & 1,090 \\
\hline Total & 924.9 & 0.1 & 53 & 185 & 733 & 30,495 & $2,427.9$ & $0.39(0.00)$ & 1,135 \\
\hline $\ln$ (Total) & 5.19 & -2.0 & 4.0 & 5.2 & 6.6 & 10.3 & 2.0 & $0.98(0.00)$ & 1,135 \\
\hline \multicolumn{10}{|c|}{ C. Minimum account size ( $\$$ thousands) $)^{\mathrm{b}}$} \\
\hline Tax exempt & $5,198.7$ & 0 & 300 & 1,000 & 5,000 & 500,000 & 17,465 & $0.23(0.00)$ & 1,203 \\
\hline Taxable & $4,315.0$ & 0 & 250 & 1,000 & 5,000 & 500,000 & 16,041 & $0.21(0.00)$ & 1,133 \\
\hline \multicolumn{10}{|c|}{ D. Median account size ( $\$$ thousands) } \\
\hline Tax exempt & 45,429 & 0 & 710 & 6,000 & 23,400 & $12,000,000$ & 393,455 & $0.10(0.00)$ & 1,065 \\
\hline Taxable & 28,902 & 0 & 11 & 602 & 3,000 & $4,158,000$ & 219,965 & $0.12(0.00)$ & 1,007 \\
\hline Total & 61,962 & 0 & 750 & 5,000 & 24,500 & $15,000,000$ & 566,675 & $0.10(0.00)$ & 1,074 \\
\hline \multicolumn{10}{|l|}{ E. Trading and fee characteristics } \\
\hline Commissions (cents per share) & 7.9 & 0 & 6 & 6 & 8 & 75 & 6.3 & $0.55(0.00)$ & 1,108 \\
\hline Annual turnover $(\%)^{\mathrm{c}}$ & 63.3 & 2 & 30 & 50 & 80 & 500 & 49.3 & $0.77(0.00)$ & 1,205 \\
\hline Minimum fee (\$) & 29,043 & 0 & 2,500 & 10,000 & 42,500 & 800,000 & 48,676 & $0.60(0.00)$ & 1,091 \\
\hline
\end{tabular}

Note: Portfolios had to report at least 12 quarters of data to be included.

${ }^{a}$ Distributions are considered to be normal when the Shapiro-Wilk statistic is close to 1 . The number in parentheses, $\operatorname{Pr}<\mathrm{W}$, represents the probability of incorrectly rejecting the null hypothesis of normalcy. Low $p$-values, such as those reported in the table, indicate distributions that are not normal. The Shapiro-Wilk test for normalcy was calculated by the method presented in Shapiro and Wilk (1965).

${ }^{\mathrm{b}}$ The smallest account accepted by a given manager.

${ }^{\mathrm{c}}$ The minimum of purchases or sales divided by average market value. 
We measured risk-adjusted returns using a traditional Jensen's alpha and the estimated intercept from the three-factor model developed by Fama and French (1993), who explained the cross-section of security returns using the following regression:

$$
R_{i, t}-r_{f, t}=\alpha_{i}+\beta_{i}\left(R_{m, t}-r_{f, t}\right)+s_{i} S M B_{t}+h_{i} H M L_{t}+\varepsilon_{i, t},
$$

where

$R_{i, t}=$ the return on portfolio $i$ in period $t$

$R_{m, t}=$ the return on the market portfolio in period $t$

$r_{f, t}=$ the risk-free rate in period $t$

$S M B=$ the difference between returns on small-capitalization portfolios and the returns on large-capitalization portfolios (that is, small minus big) with about the same weighted average of book value to market value of equity (BV/MV)

$H M L=$ the difference between returns on high-BV/MV and low-BV/MV portfolios (that is, high minus low) with about the same average size

$\varepsilon \quad=$ an error term

$S M B$ and $H M L$ are factors intended to capture, respectively, the firm-size and book-to-market effects.

Panel A of Table 2 shows the intercepts of ordinary-least-squares (OLS) regressions for the equity portfolios in our sample with at least 12 quarters of reported returns. The time period under study was 1979 through 1993, although the data were more complete for more recent years. The mean alpha is 93 basis points a quarter, or 3.7 percent annually. Exactly 85 percent of the intercepts are positive, with 31 percent of them being statistically significant. These astronomical alphas can be attributed to data biases rather than to anomalies of the particular benchmarks. For example, Panel A shows that alphas calculated by use of single-factor models produced similarly large alphas.

We mitigated the effect of any selection or reporting bias by forming a restricted sample of portfolios having returns that conformed to four quality standards. The restricted sample had four filters: Returns (1) had to be gross of fees, (2) had to be based on discretionary portfolios, (3) had to include terminated accounts, and (4) could not be from a prior firm. The performance measures for the restricted sample were as large as those for the full sample. We used both samples in the tests reported as a check on robustness.

Although the selection or reporting bias remained, we assumed that any upward bias would be the same for all portfolios. In any event, we had no reason to believe upward bias was related to a portfolio's use or nonuse of soft dollars. 


\begin{tabular}{|c|c|c|c|c|c|c|c|}
\hline Model & $N$ & $\begin{array}{l}\text { Quarterly } \\
\text { Mean } \alpha\end{array}$ & $\begin{array}{l}\text { Standard } \\
\text { Deviation }\end{array}$ & $\begin{array}{l}\text { Number } \\
\text { Positive }^{\mathrm{a}}\end{array}$ & $\begin{array}{l}\text { Number } \\
\text { Negative }\end{array}$ & $\begin{array}{l}\text { Significant } \\
\text { and Positive }\end{array}$ & $\begin{array}{c}\text { Significant } \\
\text { and Negative }\end{array}$ \\
\hline \multicolumn{8}{|l|}{ A. Intercepts $(\alpha)$} \\
\hline \multicolumn{8}{|l|}{ Fama-French (three factor) } \\
\hline Entire sample & 1,273 & $0.931 \%$ & $1.20 \%$ & $1,083(85.1)$ & 190 & $397(31.2)$ & $5(0.00)$ \\
\hline Restricted sample & 843 & 0.788 & 1.15 & $683(81.0)$ & 160 & $207(24.6)$ & $5(0.01)$ \\
\hline \multicolumn{8}{|l|}{ Jensen (single factor) } \\
\hline Fama-French market proxy & 1,273 & 0.715 & 1.03 & $1,067(83.8)$ & 206 & $265(20.8)$ & $5(0.00)$ \\
\hline S\&P 500 & 1,273 & 0.681 & 1.07 & $1,029(80.8)$ & 244 & $201(15.8)$ & $6(0.00)$ \\
\hline \multicolumn{8}{|l|}{ B. Pearson correlation coefficients } \\
\hline & \multicolumn{3}{|c|}{ Strategy Class } & & & & \\
\hline & Small Cap & Value & Growth & & & & \\
\hline$s$ & 0.66 & -0.11 & 0.11 & & & & \\
\hline$(p$-value $)$ & $(0.000)$ & $(0.000)$ & $(0.000)$ & & & & \\
\hline$N$ & 1,210 & 1,244 & 1,237 & & & & \\
\hline$h$ & -0.21 & 0.51 & -0.57 & & & & \\
\hline$(p$-value $)$ & $(0.000)$ & $(0.000)$ & $(0.000)$ & & & & \\
\hline$N$ & 1,210 & 1,244 & 1,237 & & & & \\
\hline Value & -0.08 & 1.00 & -0.39 & & & & \\
\hline$(p$-value) & $(0.05)$ & - & $(0.000)$ & & & & \\
\hline$N$ & 1,203 & 1,244 & 1,218 & & & & \\
\hline Growth & 0.21 & -0.39 & 1.00 & & & & \\
\hline ( $p$-value) & $(0.000)$ & $(0.000)$ & - & & & & \\
\hline$N$ & 1,206 & 1,218 & 1,237 & & & & \\
\hline
\end{tabular}

${ }^{\mathrm{a} A m o u n t s}$ in parentheses are percentages. 
Panel B of Table 2 provides an external check on our database. It shows classifications for three equity management styles-small-cap stock, value, and growth-that ought to be correlated with the size and book-to-market effects in Equation 1. Strategy classes were measured on a discrete scale of 0 to 3 . A measure of 3 reflected the manager's assessment that the strategy class accurately described the fund's strategy; a measure of 0 reflected an inaccurate description. Classifications 1 and 2 are hybrids. ${ }^{17}$ The correlations of $h$, the coefficient on $H M L$, with the value and growth variables are, respectively, 0.51 and -0.57 , indicating that the portfolios classified as value tended to have high estimated $h$ coefficients whereas the portfolios classified as growth tended to have low estimated $h$ coefficients. These findings suggest that the portfolios exhibited returns consistent with the strategy classifications.

Although our database did not directly identify managers' use of soft dollars, we assumed that soft dollar use was proportional to a category reported in Premium Commissions per Managed Dollar (PCMD), calculated as the average excess commission rate times annual turnover expressed as a percentage of stock portfolio value. To calculate excess commissions, we deducted 2 cents per share from a portfolio's average commission rate to net out the low-quality execution rate, thereby capturing the effect of paying up for brokerage. The results that follow are insensitive to the exact amount of the execution-only deduction. Conceptually, the deduction nets out the cost of executing easy trades but not of trades requiring skill. In addition to paying up to provide a premium that bonds execution quality, managers may pay up simply to compensate for the higher cost of executing difficult trades through full-service brokers. Although PCMD fail to distinguish between these motivations for paying up, the following tests controlled for portfolio strategies that are likely to be correlated with trade difficulty (e.g., small-cap strategies).

We accounted for the possibility that managers can pay up for brokerage both by paying higher commission rates and by increasing portfolio turnover. If bundled brokerage adds no value, increasing either commission rates or turnover will have a negative effect on portfolio returns. Alternatively, if bundled brokerage facilitates bonding and encourages managers to identify profitable trading opportunities, the benefits from reducing residual losses and capturing the returns to private information will more than offset the costs imposed by excess commission rates and increased turnover.

\footnotetext{
${ }^{17}$ The Pearson correlation coefficient between $s$, the coefficient on $S M B$, and the small-cap strategy class variable is a significant 0.66 , indicating that the small-cap variable was truly capturing the portfolios' sensitivity to movements in small-cap stocks.
} 


\section{Empirical Findings}

Many factors other than soft dollar rebates affect commission rates and turnover, including portfolio size, the number of accounts under common management, and the portfolio's management style. Table 3 illustrates how these factors affect soft dollar commission rates and turnover. The dependent variable in the first regression (first column) was the premium commission rate in cents per share. We expected a strong negative relationship between portfolio assets and excess commission rates because significant economies of scale exist in trading securities.

Table 3 also shows that index portfolios pay significantly lower average commission rates than actively managed portfolios. The index variable was a step variable that could take on four values. An index classification of 3 very accurately described a portfolio as indexed; a classification of 0 indicated that applying the term "indexed" to the portfolio's strategy would be wrong. On average, indexed portfolios pay 2 cents a share less in commissions than actively managed portfolios (i.e., the coefficient times the number of index classification steps, $0.67 \times 3$ ). The 2 cent difference is economically significant in light of a median rate of 6 cents a share. Under the unjust enrichment hypothesis, this difference should approximate the extent to which active portfolio managers attempt to unjustly enrich themselves. Under the incentive alignment hypothesis, average commissions for indexed portfolios should be lower than those for actively managed portfolios because indexed portfolios are presumed to use considerably less research and because indexed portfolio trades are presumed to be uninformed and to require little or no quality-assuring brokerage premium.

The regression in the first column also shows that an increase in the number of accounts managed in each portfolio, $\ln$ (Accounts), increases commission rates, which is consistent with our prediction that a larger number of accounts increases the administrative work of the broker booking the trades. If the manager is trading a specific security for only one large account, for example, the broker need book only one trade. If the manager is trading for a large number of accounts, the administrative work increases dramatically. An increase in the administrative costs of trading should also decrease the level of portfolio turnover. The predicted negative relationship between the number of accounts in a portfolio and turnover appears in the second regression. In all, the independent variables explain 17 percent and 26 percent of the crosssectional variation in, respectively, commissions and turnover.

Strategy classes, or management styles, may pick up variations in Section 28(e)'s safe harbor protection that allow managers to separate traditional soft 
Table 3. Cross-Sectional OLS Regressions of Commissions and Turnover on Portfolio Variables, 1993

\begin{tabular}{|c|c|c|c|c|c|c|}
\hline \multirow[b]{2}{*}{ Measure } & \multicolumn{2}{|c|}{$\begin{array}{l}\text { Average Soft Dollar } \\
\text { Commission Rate }\end{array}$} & \multicolumn{2}{|c|}{$\begin{array}{l}\text { Annual } \\
\text { Turnover }\end{array}$} & \multicolumn{2}{|c|}{$\begin{array}{l}\text { Premium Commissions } \\
\text { per Managed Dollar }\end{array}$} \\
\hline & $\begin{array}{l}\text { Parameter } \\
\text { Estimate }\end{array}$ & $p$-Value & $\begin{array}{l}\text { Parameter } \\
\text { Estimate }\end{array}$ & $p$-Value & $\begin{array}{l}\text { Parameter } \\
\text { Estimate }\end{array}$ & $p$-Value \\
\hline Intercept & 8.01 & $0.000^{* * *}$ & 86.38 & $0.000^{* * *}$ & 385.37 & $0.000^{\star \star *}$ \\
\hline $\ln$ (Assets) & -0.91 & $0.000^{\star * *}$ & 1.00 & 0.275 & -30.06 & $0.000^{\star * *}$ \\
\hline $\ln$ (Accounts) & 1.05 & $0.000^{* * *}$ & -3.21 & $0.001^{* * *}$ & 35.00 & $0.000^{* * *}$ \\
\hline \% Tax-exempt assets & -0.90 & 0.16 & -5.00 & 0.299 & -76.48 & $0.077^{\star}$ \\
\hline Annual turnover & -0.01 & $0.001^{\star * \star}$ & & & & \\
\hline $\begin{array}{l}\text { Average soft dollar } \\
\text { commission }\end{array}$ & & & -0.79 & $0.001^{\star * *}$ & & \\
\hline Strategy classes & & & & & & \\
\hline Value & 0.220 & 0.271 & -4.22 & $0.006^{\star \star *}$ & 2.33 & 0.864 \\
\hline Growth & 0.59 & $0.005^{\star \star *}$ & -0.35 & 0.823 & 35.00 & $0.012^{\star *}$ \\
\hline Small capitalization & -0.31 & $0.088^{*}$ & 1.21 & 0.382 & 1.45 & 0.907 \\
\hline Broad market & 0.01 & 0.955 & -1.38 & 0.357 & -8.27 & 0.540 \\
\hline Market timer & -0.26 & 0.440 & 0.13 & 0.959 & -19.32 & 0.393 \\
\hline Convertible & -0.19 & 0.573 & -7.41 & $0.003^{\star * *}$ & -53.20 & $0.018^{\star \star}$ \\
\hline Sector rotator & 0.04 & 0.895 & 5.53 & $0.006^{\star * *}$ & 47.21 & $0.009^{* * *}$ \\
\hline Index & -0.67 & $0.034^{\star \star}$ & -13.20 & $0.000^{* * *}$ & -53.06 & $0.012^{\star \star}$ \\
\hline Contrarian & -0.12 & 0.626 & -5.65 & $0.002^{\star \star *}$ & -25.76 & 0.115 \\
\hline Theme selection & -0.05 & 0.822 & -0.50 & 0.779 & -12.28 & 0.447 \\
\hline High yield & 0.21 & 0.401 & -1.699 & 0.376 & 1.73 & 0.920 \\
\hline Core & -0.017 & 0.930 & -3.37 & $0.018^{\star \star}$ & -17.30 & 0.176 \\
\hline Hedged equity & -0.01 & 0.988 & 25.81 & $0.000^{* * *}$ & 129.01 & $0.000^{* * *}$ \\
\hline Socially responsible & -0.21 & 0.406 & -2.45 & 0.205 & -27.24 & 0.116 \\
\hline Technical & 0.96 & $0.001^{* * *}$ & 12.39 & $0.000^{* * *}$ & 133.08 & $0.000^{* * *}$ \\
\hline Mutual fund timing & -2.37 & $0.001^{* * *}$ & 29.86 & $0.000^{\star * *}$ & -204.71 & $0.000^{* * *}$ \\
\hline$N$ & 961 & & 961 & & 961 & \\
\hline$F$-value & $11.04^{* \star *}$ & & $17.43^{\star * *}$ & & $11.37^{\star * *}$ & \\
\hline Adjusted $R^{2}$ & 0.17 & & 0.26 & & 0.17 & \\
\hline
\end{tabular}

Note: Annual turnover is the minimum of purchases or sales divided by average market value. The variable $\ln$ (Assets) is the natural $\log$ of portfolio assets; $\ln$ (Accounts) is the natural $\log$ of the number of accounts managed.

*Significant at the 10 percent level.

** Significant at the 5 percent level.

$* * *$ Significant at the 1 percent level. 
dollar research rebates from the implicit research rebates provided by fullservice brokers. Section 28(e) permits investment managers to pay up for brokerage in exchange for investment research as long as the extent of paying up is commensurate with the value of the research and other services received. By SEC ruling, this protection is available only for trades conducted on an agency basis (i.e., those involving payment of a commission). Trades executed on a principal basis, such as those executed through the National Association of Securities Dealers Automated Quotation, receive no safe harbor protection. This restriction might cause managers who fear liability for accepting soft dollar research rebates on dealer trades to engage in less paying up for third-party research, which would affect the relationship between strategy class and PCMD. To the extent that managers can effectively replace soft dollar brokerage with full-service brokerage, however, the lack of safe harbor protection will not affect the relationship because premium commissions per managed dollar fail to screen out bundled full-service brokerage. Therefore, it is difficult to know whether the relationship between strategy classes and bundled brokerage is being driven by variations in Section 28(e) safe harbor protection.

The regression reported in the third column of Table 3 shows how PCMD are related to portfolio characteristics. The positive sign on the number of accounts suggests that soft dollar use decreases as client concentration increases and monitoring improves, a result that is consistent with both the unjust enrichment hypothesis and the incentive alignment hypothesis. Also, some types of portfolios pay up less (e.g., index and mutual fund timing), whereas others pay up more (e.g., growth, sector rotator, and hedged equity). ${ }^{18}$

Table 4 shows the apparent effect of soft dollars on risk-adjusted returns. The first column reports the results of a univariate test of the association, which shows that PCMD are associated with higher risk-adjusted returns at the 99 percent confidence level. The risk-adjusted returns-reported in decimal units, so 0.10 represents a 10 percent return-are net of commissions. The suggestion is that, with turnover and other factors held constant, a 1 cent increase in soft dollar commission rates increases risk-adjusted performance by 7.6 basis points a quarter. Although our database is subject to performance-reporting biases, the bias is presumably unrelated to either soft dollar use or measured PCMD. The positive relationship we found between portfolio performance and PCMD strongly suggests that soft dollars increase the welfare of portfolio beneficiaries.

${ }^{18}$ Although not reported here, we found the effect of portfolio size and number of accounts to be qualitatively unaffected by excluding various strategy class variables. 


\section{Table 4. The Effect of Soft Dollars on Performance: Estimated Alphas from Fama-French (1993) OLS Regressions, 1979-93}

\begin{tabular}{|c|c|c|c|}
\hline Measure & $\begin{array}{l}\text { Univariate Test: } \\
\text { Alpha on PCMD }\end{array}$ & $\begin{array}{l}\text { Multivariate Test: } \\
\text { Alpha on PCMD }\end{array}$ & $\begin{array}{l}\text { Multivariate Test: } \\
\text { Alpha on PCMD } \\
\text { (including strategy } \\
\text { class variables) }\end{array}$ \\
\hline Intercept & $0.69 * \star \star$ & $1.66^{\star \star \star}$ & $1.21^{\star \star \star}$ \\
\hline PCMD & $0.076^{\star \star \star}$ & & \\
\hline PCMD residual & & $0.060^{\star * *}$ & $0.037^{\star * \star}$ \\
\hline $\ln$ (Assets) & & $-0.070^{* * *}$ & $-0.041^{*}$ \\
\hline $\ln$ (Accounts) & & 0.024 & 0.031 \\
\hline \% Tax-exempt assets & & $-0.509^{\star \star *}$ & $-0.330^{\star \star *}$ \\
\hline \multicolumn{4}{|l|}{ Strategy classes } \\
\hline Value & & & $-0.075^{\star \star}$ \\
\hline Growth & & & $0.155^{\star \star *}$ \\
\hline Small capitalization & & & $0.204^{\star \star *}$ \\
\hline Broad market & & & $-0.085^{\star \star}$ \\
\hline Market timer & & & $-0.111^{*}$ \\
\hline Convertible & & & $-0.160 * * *$ \\
\hline Sector rotator & & & -0.016 \\
\hline Index & & $-0.276^{\star \star \star}$ & $-0.204^{\star * *}$ \\
\hline Contrarian & & & -0.027 \\
\hline Theme selection & & & 0.026 \\
\hline High yield & & & -0.060 \\
\hline Core & & & $-0.103^{\star * *}$ \\
\hline Hedged equity & & & $0.379^{\star \star \star}$ \\
\hline Socially responsible & & & -0.026 \\
\hline Technical & & & 0.083 \\
\hline Mutual fund timing & & & $-0.277^{* *}$ \\
\hline$N$ & 1,102 & 967 & 961 \\
\hline$F$-value & $80.65^{\star \star \star}$ & $23.05^{\star \star *}$ & $17.41^{\star * \star}$ \\
\hline Adjusted $R^{2}$ & 0.07 & 0.10 & 0.25 \\
\hline
\end{tabular}

Note: Intercepts from OLS regressions of equity and cash quarterly portfolio excess returns were calculated from Equation 1. To avoid colinearity, the PCMD residual term was the OLS residual from having the product of PCMD as the independent variable and all other factors as independent variables. The residual term represents the portion of soft dollar brokerage left unexplained by the remaining independent variables.

*Significant at the 10 percent level.

${ }^{* *}$ Significant at the 5 percent level.

$* * \star$ Significant at the 1 percent level. 
To bring control variables into the analysis, we accounted for the correlation between PCMD and the other independent variables. The PCMD variable was first regressed against the other control variables. The residuals from that regression were used as the independent variable in the second and third regressions of Table 4 . The significantly positive relationship between soft dollars and performance remained after we introduced the effects of these control variables. Index funds appear to underperform their actively managed counterparts even in the presence of other strategy-class control variables, although this result may come from selection and reporting biases. The relatively low returns of portfolios with a high proportion of pension assets is consistent with results reported by Ambachtsheer (1994); the relatively high returns of hedged equity portfolios is consistent with results reported by Schneeweis and Spurgin (1998).

The positive relationship between PCMD and performance withstands further tests of robustness. Table 5 reports our examination of the relationship between PCMD and performance for two samples and two estimation procedures. The regression reported in the first column estimated the relationship for portfolios having returns that conformed to the four quality criteria given in the discussion of Table 2 . The positive relationship between bundled brokerage and performance is shown to be significant at the 99 percent level of confidence, as it is for all the tests of robustness. The data on commission rates and turnover (hence our soft dollar proxy) were for only the most recent set of returns and thus may be less relevant to the earlier return data. The data on commission rates and turnover should be related to a portfolio's strategy (as shown in Table 3), which is stable over time. To address this potential mismatch between return data and brokerage data, we used in the next estimation of the relationship only the most recent five years of returns, 1989-1993. As in the regression reported in the first column, quarterly risk-adjusted performance measured for the most recent years (shown in the second column) tends to increase with the use of soft dollars.

Some estimates of risk-adjusted performance are better than others; that is, some estimated alphas are less noisy than others. To place greater emphasis on those observations with more reliable estimates of performance, we performed a weighted-OLS analysis on the entire sample using the reciprocal of the alpha's standard error (SE) as the weight. The results are reported in the third column of Table 5. Finally, we used the traditional Jensen's alpha to estimate the relationship between soft dollars and performance, as reported in the fourth column. In both cases, we found greater soft dollar use to be associated with greater risk-adjusted performance at the 99 percent level of 
Table 5. Robustness Tests of the Effect of Soft Dollar Brokerage on Performance, 1979-93

\begin{tabular}{|c|c|c|c|c|}
\hline Measure & $\begin{array}{l}\text { Restricted } \\
\text { Sample }\end{array}$ & $\begin{array}{l}\text { 1989-93 } \\
\text { Returns }\end{array}$ & $\begin{array}{c}\text { OLS Weighted } \\
\text { by the SE } \\
\text { Reciprocal }\end{array}$ & $\begin{array}{c}\text { Jensen's } \\
\text { Alpha }\end{array}$ \\
\hline Intercept & $0.95^{\star \star \star}$ & $1.09^{\star \star \star}$ & $0.84^{\star \star \star}$ & $0.95^{\star \star \star}$ \\
\hline PCMD residual & $0.042^{\star \star \star}$ & $0.037^{\star * *}$ & $0.028^{\star * \star}$ & $0.029^{* * *}$ \\
\hline $\ln$ (Assets) & -0.001 & -0.024 & $-0.030^{\star *}$ & $-0.062^{\star * \star}$ \\
\hline $\ln$ (Accounts) & -0.018 & -0.018 & 0.021 & $0.057^{* * *}$ \\
\hline \% Tax-exempt assets & $-0.329^{\star *}$ & $-0.394^{\star \star *}$ & $-0.156^{\star}$ & $-0.261^{* * *}$ \\
\hline \multicolumn{5}{|l|}{ Strategy classes } \\
\hline Value & -0.030 & $-0.806^{\star \star}$ & $-0.055^{\star \star}$ & $0.064^{*}$ \\
\hline Growth & $0.173^{\star * *}$ & $0.149^{\star \star *}$ & $0.120^{\star * *}$ & 0.032 \\
\hline Small capitalization & $0.212^{\star \star \star}$ & $0.260^{\star \star \star}$ & $0.138^{\star \star \star}$ & $0.052^{*}$ \\
\hline Broad market & -0.059 & $-0.074^{\star \star}$ & $-0.043^{\star}$ & $-0.057^{\star}$ \\
\hline Market timer & 0.040 & 0.039 & 0.075 & 0.058 \\
\hline Convertible & -0.058 & $-0.122^{\star}$ & $-0.110^{* * *}$ & -0.092 \\
\hline Sector rotator & 0.038 & 0.013 & -0.017 & 0.019 \\
\hline Index & $-0.157^{\star *}$ & $-0.171^{\star \star \star}$ & $-0.152^{\star \star *}$ & -0.076 \\
\hline Contrarian & -0.012 & -0.023 & -0.027 & -0.010 \\
\hline Theme selection & 0.029 & 0.028 & $0.059^{\star}$ & 0.009 \\
\hline High yield & -0.049 & -0.50 & $-0.053^{\star}$ & 0.048 \\
\hline Core & $-0.146^{\star \star *}$ & $-0.073^{\star *}$ & $-0.059^{\star * *}$ & $-0.066^{\star *}$ \\
\hline Hedged equity & $0.271^{\star * *}$ & $0.385^{\star * *}$ & $0.132^{\star *}$ & $0.334^{* * *}$ \\
\hline Socially responsible & -0.094 & $-0.086^{\star}$ & -0.009 & -0.023 \\
\hline Technical & 0.036 & $0.117^{\star *}$ & $0.093^{\star *}$ & 0.052 \\
\hline Mutual fund timing & -0.233 & $-0.311^{* *}$ & $-0.165^{\star}$ & $-0.211^{*}$ \\
\hline$N$ & 686 & 961 & 961 & 961 \\
\hline$F$-value & $11.49^{\star \star \star}$ & $17.42^{\star \star *}$ & $18.20^{* * *}$ & $6.52^{\star \star *}$ \\
\hline Adjusted $R^{2}$ & 0.23 & 0.25 & 0.26 & 0.10 \\
\hline
\end{tabular}

Note: Intercepts from OLS regressions of equity and cash quarterly portfolio excess returns were calculated from Equation 1. The dependent variable is the estimated alpha from the performance regressions. The PCMD variable is the OLS residual from having the product of PCMD as the dependent variable and all other factors as independent variables.

* Significant at the 10 percent level.

${ }^{*}$ Significant at the 5 percent level.

$\star \star \star$ Significant at the 1 percent level. 
confidence. ${ }^{19}$ These results are consistent with the incentive alignment hypothesis but not the unjust enrichment hypothesis.

If managers use soft dollars to unjustly enrich themselves in a competitive labor market, the expectation of being able to capture this value should be reflected in lower management fees. But if soft dollars align managers' interests in the absence of other monitoring mechanisms, management fees should be either unrelated or positively related to PCMD. Table 6 shows the effect of PCMD on management fees, expressed in basis points, for various account sizes. Management fees appear to be unrelated to soft dollar use regardless of account size. Interestingly, fees on larger accounts tend to increase with past performance, which suggests that managers gain bargaining power if they can report recent positive risk-adjusted returns. The expected negative relationship between indexing and management fees is clear in Table 6. Apparently, portfolios with relatively more pension assets tend to have lower management fees. The relationship between PCMD and management fees is generally positive but statistically insignificant. Managers apparently do not accept lower management fees in an attempt to compete for the opportunity to unjustly enrich themselves through soft dollar brokerage. These results fail to reject the incentive alignment hypothesis and are inconsistent with the unjust enrichment hypothesis.

These results withstood the same tests of robustness as the relationship between PCMD and performance. For the restricted sample of portfolios, the regression reported in the first column of Table $\mathbf{7}$ indicates an insignificant positive relationship between soft dollar use and management fees. Again, the data concerning management fees covered the most recently reported time period because older return data may have been mismatched with the more recent data on management fees. In any event, no detectable relationship exists between PCMD and management fees for the most recent set of return data, shown in the second column. Weighting observations by the reciprocal of the alpha's standard error, shown in the third column, significantly strengthened the relationship and the explanatory power of the regression, as measured by the adjusted $R^{2}$, which suggests that investors are willing to pay higher management fees when historical risk-adjusted returns are less noisy. Finally, as the fourth column shows, measuring performance with a traditional Jensen's alpha failed to identify a significant relationship between soft dollars and management fees. ${ }^{20}$

\footnotetext{
${ }^{19}$ Although not reported here, we also weighted observations based on portfolio size and obtained qualitatively identical results. The results were essentially the same when we used various combinations of sample construction and estimation procedures.

${ }^{20}$ The results were qualitatively unaffected by weighting observations by portfolio size or by using various combinations of sample construction and estimation procedures.
} 
Table 6. The Effect of Soft Dollars on 1993 Management Fees

\begin{tabular}{|c|c|c|c|c|}
\hline Measure & $\begin{array}{c}\text { Fee: } \\
\text { Account Size } \\
\$ 1 \text { Million }\end{array}$ & $\begin{array}{c}\text { Fee: } \\
\text { Account Size } \\
\$ 10 \text { Million }\end{array}$ & $\begin{array}{c}\text { Fee: } \\
\text { Account Size } \\
\text { \$50 Million }\end{array}$ & $\begin{array}{c}\text { Fee: } \\
\text { Account Size } \\
\$ 100 \text { Million }\end{array}$ \\
\hline Intercept & $117.86^{\star \star \star}$ & $80.62^{\star \star \star}$ & $67.28^{\star * *}$ & $66.43^{\star \star \star}$ \\
\hline Alpha & 5.86 & $5.33^{\star *}$ & $6.41^{\star \star \star}$ & $5.70^{\star \star \star}$ \\
\hline PCMD residual & -1.87 & 0.65 & 0.90 & 0.61 \\
\hline $\ln$ (Assets) & $13.54^{\star \star \star}$ & -0.05 & 0.10 & -0.63 \\
\hline $\ln$ (Accounts) & $-15.24^{\star \star *}$ & 1.08 & -0.51 & -0.33 \\
\hline \% Tax-exempt assets & -13.73 & -13.04 & $-16.64^{* * *}$ & $-17.53^{\star \star *}$ \\
\hline Index & $-19.09 * *$ & $-10.02^{* \star *}$ & $-6.56^{\star \star \star}$ & $-5.58^{* \star}$ \\
\hline$N$ & 360 & 360 & 360 & 360 \\
\hline$F$-value & $3.30^{\star \star *}$ & $4.65^{\star \star \star}$ & $9.26^{\star \star \star}$ & $8.10^{\star \star *}$ \\
\hline Adjusted $R^{2}$ & 0.04 & 0.06 & 0.12 & 0.11 \\
\hline
\end{tabular}

Note: Alpha is the intercept of the OLS regression of portfolio returns on the Fama-French risk factor proxies.

${ }^{* *}$ Significant at the 5 percent level.

$* * \star$ Significant at the 1 percent level.

Table 7. Robustness Tests of the Effect of Soft Dollars on 1993 Management Fees

\begin{tabular}{|c|c|c|c|c|}
\hline Measure & $\begin{array}{l}\text { Restricted } \\
\text { Sample }\end{array}$ & $\begin{array}{l}\text { 1989-93 } \\
\text { Returns }\end{array}$ & $\begin{array}{l}\text { OLS Weighted by } \\
\text { the SE Reciprocal }\end{array}$ & $\begin{array}{l}\text { Jensen’s } \\
\text { Alpha }\end{array}$ \\
\hline Intercept & $65.65^{\star \star \star}$ & $68.14^{\star \star \star}$ & $58.23^{\star * *}$ & $68.29^{\star \star \star}$ \\
\hline Alpha & $5.85^{\star \star}$ & $4.51^{\star \star *}$ & $8.18^{\star \star \star}$ & $5.68^{\star \star \star}$ \\
\hline PCMD residual & 1.46 & 0.75 & 1.01 & 0.79 \\
\hline $\ln$ (Assets) & 0.098 & -0.87 & -0.65 & -0.60 \\
\hline $\ln$ (Accounts) & -1.42 & 0.01 & 0.09 & -0.53 \\
\hline \% Tax-exempt assets & $-22.82^{\star \star \star}$ & $-17.59 * \star \star$ & $-14.52^{\star \star \star}$ & $-18.49^{\star \star \star}$ \\
\hline Index & $-6.04^{\star \star}$ & $-6.03^{\star \star}$ & $-9.58^{\star \star \star}$ & $-6.40^{\star \star}$ \\
\hline$N$ & 248 & 360 & 360 & 360 \\
\hline$F$-value & $5.61^{\star \star \star}$ & $7.55^{\star \star \star}$ & $28.39 * \star \star$ & $7.49^{\star \star \star}$ \\
\hline Adjusted $R^{2}$ & 0.10 & 0.10 & 0.31 & 0.10 \\
\hline
\end{tabular}

Note: The dependent variable was the fee for an account size of $\$ 100$ million. Alpha is the intercept of the OLS regression of portfolio returns on the Fama-French risk factor proxies or a single-factor performance model, as indicated.

** Significant at the 5 percent level.

$\star * *$ Significant at the 1 percent level. 


\section{Policy Analysis}

We consider here several implications of our analysis for public policy makers, government regulators, and self-regulatory organizations. We discuss relational trust, principal trading, electronic trading and information processing, and disclosure reform.

\section{Relational Trust}

Why soft dollar brokerage should generate persistent risk-adjusted excess returns is a critical question that cries out for an answer, and the answer bears directly on sound public policy. If, as we argue, market participants are quick to mimic those whose methods prove superior, then all excess portfolio returns should be competed away in the long run. One explanation for persistent excess returns is that managers truly perceive a nonzero risk of civil suit or negative publicity when using soft dollars and believe that this risk must be compensated for by superior portfolio returns. A more plausible explanation is that the know-how to generate superior portfolio performance lies to a large extent in the manager's ability to establish trusting relationships with brokers and that paying up-whether for reputable full-service brokerage or for bonded soft dollar brokerage-is a necessary part of the process. To generate persistent excess returns, this know-how must be difficult for outsiders to discern or mimic. Trust is an effective mechanism for enforcing exclusive property rights to proprietary information about mispriced securities that results from the manager's investment research. The effectiveness of trust explains why rival managers are unable to generate superior portfolio performance simply by paying up: By itself, paying up does not create a trusting relationship. It also explains why investment managers regard their brokerage allocation practices as an extremely sensitive subject.

Our information suggests that managers base their brokerage allocation decisions on three factors: the broker's ability to perform high-quality executions, the value of the research the broker provides, and "the relationship," which is shorthand for the reciprocal trust the parties place in one another. This relationship surely extends to the manager's trust in the broker's care and loyalty in executing trades. The evidence suggests that it also extends to the broker's stewardship over any information about portfolio composition or long-term investment strategy the manager may reveal to allow the broker to recommend worthwhile research or to trade effectively on behalf of the 
portfolio. The broker, given his inability to compel the manager to fulfill either the letter or the spirit of the soft dollar obligation, obviously places substantial trust in the manager. The broker's trust in the manager explains why a research rebate is superior to a cash rebate paid by the broker directly to the portfolio. Any form of advance rebate paid by the broker bonds the quality of the broker's executions, but a research rebate gives the manager the wherewithal to generate the difficult trades on which the broker hopes to earn premium commissions. By taking the rebate in research rather than in cash paid to the portfolio, managers bond their promise to work diligently to identify mispriced securities leading to trades that allow brokers to recoup their investments. The more appropriate the research products a broker recommends, all else being equal, the more difficult the manager's trades. The outcome is a higher commission rate on all the manager's trades, which allows the manager to pay down the soft dollar account balance more quickly.

The story that emerges is that high-quality brokerage (the execution of difficult trades) is not a commodity. It is a uniquely tailored service whose attributes are impossible to measure at the moment the transaction takes place and difficult to measure on a one-time basis even with the passage of time. The difficult trades that create the need for high-quality brokerage require close cooperation between the parties in a process that must be viewed as joint production. Because the parties' expectations are legally unenforceable, they must rely on extra-legal methods of assuring performance, such as trust. Seen in this light, institutional securities brokerage relies on what economists call "relational investing."

In relational investing, trust is a durable asset that requires one or both parties to make ex ante investments specific to the relationship. Over the long run, these investments must earn a competitive return. In the case of soft dollars, the broker makes a sunk capital investment in providing the manager with up-front research and earns a commission premium thereafter. The manager makes an investment (on behalf of the portfolio) in the broker by entrusting the broker with sensitive information about mispriced securities, portfolio composition, trading strategy, and so on. Unlike the broker's investment, however, the manager's investment involves no cash outlay that would lead to an accounting entry; the cost is a pure opportunity cost consisting of the value of the portfolio the manager puts at risk when entrusting the broker or brokers with sensitive information.

Our assessment of the welfare effects of soft dollar brokerage is not meant to suggest that traditional full-service brokerage is in any way deficient or inferior. To the contrary, in our view, full-service brokers probably provide 
the highest quality execution services in the industry. ${ }^{21}$ Our point is simply that by providing an up-front performance bond, soft dollars assure a manager of receiving higher quality execution when patronizing a broker whose reputation has not been widely established over a long course of dealing than the manager could otherwise expect. No doubt both traditional full-service brokerage and soft dollar brokerage provide unique advantages and disadvantages to investment managers and their clients in various circumstances. But bundled full-service brokerage, being the status quo, requires no justification in the public policy realm.

The notion that soft dollars establish an effective performance bond that supports relational trust may explain why soft dollars were so effective in helping start-up brokerage houses enter the market following the deregulation of fixed commissions. By allowing these unknown entrants to post an immediate performance bond, and thereby to quickly establish a modicum of trust with managers, soft dollars helped them compete with full-service brokers whose reputations had been established over decades of reputable business dealings. In the current market, soft dollars increase competition by reducing the cost to managers of establishing trust and allowing them to use a larger pool of brokers than otherwise. In the absence of the ability to rely on an immediate performance bond, managers would be forced to use a smaller pool of brokers with whom they have taken the time to establish long-term relations or whose reputations are already well established. This situation could easily compromise the informed manager's anonymity, leading to leakage, price impact, poor execution quality, and reduced portfolio performance.

\section{Principal Trading}

According to the SEC's letter ruling in Fund Monitoring Services, Inc., principal trades fall outside Section 28(e)'s safe harbor protection, which increases the cost to a manager of establishing relational trust with broker/dealers when they are acting as principals. We see no reason why relational trust is any less important in the context of principal trading, however, than in an agency setting or why a soft dollar rebate is any less effective in creating or reinforcing this trust. So-called "riskless principal trades," in which the broker/dealer simultaneously arranges both sides of the trade, appear to be much like agency trades when viewed from one side or the other. Yet because the manager is not necessarily privy to the spread, and because the broker/dealer

\footnotetext{
${ }^{21}$ Our information suggests that the research full-service brokers provide is not so highly regarded in the industry. Our belief is that full-service brokers are capable of producing highquality conclusory research but that because of the measurement and favoritism problems, they have a difficult time assuring clients of its value.
} 
is not a fiduciary, the benefit of a performance bond in helping the manager prevent overreaching or self-dealing by the broker/dealer may be even more compelling than in the agency setting.

Some of the broker/dealers' misaligned incentives are reduced when they actually put their own capital at risk in executing trades, but the misaligned incentives are not eliminated. When broker/dealers buy or sell out of their own inventory, the manager can be sure they have strong incentives to avoid price impact on the transaction. The reason is that broker/dealers bear any losses resulting from their own carelessness. Even in this setting, however, broker/dealers can impose losses on a portfolio beyond the transaction at hand by overreaching or self-dealing. For example, to allow a broker/dealer to perform effectively, the manager might find it advantageous to provide the dealer with sensitive information that the dealer could misuse in separate transactions to the dealer's advantage at the expense of the portfolio. Moreover, any long-term investments the manager makes in establishing a working relationship with a broker/dealer may be subject to "hold-up" or expropriation. The broker/dealer might insist on adjusting the expected spread, ex post, to capture a greater share of the value accruing to the relationship than the manager originally anticipated. The number of possibilities is large, and their contours complex. In our view, an up-front soft dollar rebate provides the manager with one additional and effective tool to ensure that the portfolio receives best execution and the maximum benefit from investment research.

The SEC's ruling that principal trades fall outside the safe harbor has very likely affected managers' trading decisions. At the margin, managers have probably tended to favor agency trades over principal trades, perhaps inefficiently so. This tendency might have increased the frequency with which managers interpose a broker between themselves and the ultimate trader in dealer markets. The unjust enrichment hypothesis suggests that managers do so simply to capture wealth by inducing their portfolios to pay their research bills on dealer trades while retaining safe harbor protection. The incentive alignment hypothesis suggests that managers use interpositioning to gain added anonymity through the use of a bonded broker, perhaps because they fear liability for soft dollar rebates when trading on a principal basis.

When seeking the benefits of bundled brokerage on principal trades, managers have probably tended to favor full-service brokers because the research managers receive from full-service brokers, being provided on a strictly informal basis, has until recently received little scrutiny from the SEC.

Disentangling the welfare effects of the SEC's exclusion of principal trades from safe harbor protection is not easy, but we hope that in reviewing 
its position, the SEC will give careful consideration to the subtleties of the incentive alignment hypothesis and its favorable implications for the welfare of portfolio beneficiaries.

\section{Electronic Trading and Information Processing}

The electronics revolution has obviously far surpassed what most of us envisioned even a decade ago, especially where the trading opportunities available to individual investors are concerned. The advent of electronic retail trading over the Internet appears to have substantially increased volatility, especially in thinly traded Internet and other high-tech stocks whose floats are limited because of share transfer restrictions. The result is additional noise in market prices and a reduction in the ability of investment managers to adequately assess the quality of execution they receive when they trade these stocks. Our view is that added noise increases the benefits from relational trust for those managers who specialize in such stocks and thus increases the extent to which they pay up for either full-service or soft dollar brokerage.

For institutional investors, advances in electronic technology have brought a proliferation of electronic communication networks (ECNs) as alternative trading forums. The SEC has encouraged institutions to send an increasing share of their trades to ECNs, and these networks, whose commission costs are close to those of discount brokers, have apparently indeed captured an increasing share of institutional brokerage. But it is unclear whether ECNs have the ability to do anything more than cross easy trades that would not generate price impact if executed on an exchange. To the extent that ECNs are simply diverting easy trades away from exchanges (leaving the exchanges with a higher proportion of difficult trades), the benefit investment managers receive from trading cheaply through ECNs will be more than outweighed by higher transaction costs in exchange trading. The reason is that easy trades provide those who execute on an exchange with greater ability to obscure their difficult, informed trades. As easy trades are diverted to ECNs, the transaction costs of trading a higher proportion of difficult trades on an exchange should rise, which should increase the benefit from relational trust and from bonded soft dollar brokerage. Only if ECNs succeed in converting trades that would otherwise be difficult into easy-toexecute commodity-type trades will this trend reduce total transaction costs and generate net benefits in the market. If such diversion occurs (and to the extent that it occurs), the exchanges will naturally wither and any form of paying up will gradually vanish. 


\section{Disclosure Reform}

The SEC's 1998 Inspection Report recommended detailed internal record keeping and disclosure of research and other services bundled into brokerage by broker/dealers, investment advisors, and investment companies. In light of the incentive alignment hypothesis, we believe the SEC must take great care to ensure that this recommendation will not require successful investment managers to reveal anything that could be used by rival managers or market interlopers to discern or mimic their brokerage allocation practices. Failure to make such assurances could reduce managers' incentives to make the ex ante investments necessary to discover mispriced securities and thus could substantially undermine market efficiency.

Moreover, detailed record keeping and disclosure are extremely costly, and their benefits for advisory clients may fail to justify the costs. In assessing the costs and benefits of additional record keeping and disclosure, the SEC should devote some attention to tailoring the requirements to the situation at hand to minimize their burden. Alternative methods of achieving the same or similar results should be seriously considered.

Our reading of the Inspection Report suggests that the auditors found relatively few improprieties among public investment companies compared with private investment managers and the managers of unregulated portfolios. Thus, the current system appears to be working well. Investors in public investment companies are the least able to protect themselves because of their tremendous collective action problem and their high costs of directly contracting with their funds. Therefore, SEC oversight specifically tailored to public investment companies is quite appropriate.

Private portfolio managers and their clients are in an entirely different situation. They do have the practical ability to enter into explicit contracts (to prohibit bundled brokerage, for example, or to insist on enhanced record keeping and disclosure) and to engage in direct monitoring. Nothing in the Inspection Report's recommended enhancements to record keeping and disclosure improve on what private advisory clients can do (or affirmatively refrain from doing) on their own. Because detailed record keeping and disclosure are extremely costly, rational clients probably allow some "improprieties" to go unnoticed or unpunished. Private clients apparently are choosing not to spend a dollar to save a dime, contrary to what the Inspection Report would require. ${ }^{22}$

\footnotetext{
${ }^{22}$ To be exact, the Inspection Report would impose the costs of enhanced record keeping and disclosure directly on investment managers and broker/dealers, not on clients. Anyone familiar with basic economic theory understands that clients will bear this burden to exactly the same extent as if the costs were imposed on them directly.
} 
One cannot infer from the available evidence that the current system has failed, and to compel market participants to spend substantial resources doing what they have privately declined to do could be a grave mistake.

Section 28(e) (2) grants the SEC

rulemaking authority to require that investment advisers disclose their soft dollar practices and procedures, as "necessary or appropriate in the public interest or for the protection of investors." (Inspection Report, Section II, C)

In the case of private advisory clients, there is no public interest to protect and no market failure to justify intrusive regulation. Our view is that the SEC should continue its focus on public investment companies and leave private advisory clients and their managers largely to their own devices when it comes to prescribing record keeping and disclosure. ${ }^{23}$

This issue is important because the Inspection Report and earlier SEC interpretations of Section 28(e) are apparently seeking to usurp much of agency law. That body of law prescribes various default rules that govern the parties' relationship when they have neglected to agree to the contrary. The Inspection Report suggests that private parties should be prohibited from opting out of onerous disclosure requirements. We see no reason why private parties should be prevented from agreeing to a one-time blanket disclosure, with the client retaining the right to conduct $a d$ hoc audits and sue for breach in the event the client discovers substantial improprieties during the course of the relationship. Clients surely have the right to insist on detailed disclosure, but at least according to agency law, they also have the right to waive disclosure, trust their agents, and get on with their business. The very motivation for trust, which we assert is costly to establish, is that it saves the parties valuable resources in monitoring, bonding, or otherwise scrutinizing the relationship.

The SEC's interpretation of the Section 28(e) safe harbor intrudes on agency law in another important, if less obvious, way. According to the SEC, a manager's receipt of any kind of rebate from a broker raises a potential conflict of interest that could reflect a breach of the manager's duty of loyalty to the client. It is on the basis of this potential conflict that the SEC and the Inspection Report premise the call for detailed disclosure. According to the incentive alignment hypothesis, however, the manager's receipt of an advance rebate is essential to bond the broker's performance on behalf of the portfolio. The receipt of an advance rebate is a prudent business decision and provides an affirmative defense to any claim that the manager has breached her duty of

\footnotetext{
${ }^{23}$ Even in the case of public investment companies, we believe the SEC should focus on helping investors assess outputs, rather than inputs, by prescribing standardized performance measures, as it has indeed done to some extent.
} 
loyalty. Given that such a rebate is appropriate, the manager's decision as to the exact form the rebate takes (whether research reports, computer systems, or airline tickets to an important research seminar) is purely a business decision that, under agency law, may or may not involve a breach of the manager's duty of due care. Managers who are acting prudently will naturally seek to identify and use those research products (which may or may not comport with the SEC's interpretation of that term) that maximize the benefit to the client, whether the products come from full-service or soft dollar brokers.

The prudence of the manager's decisions is covered by the business judgment rule. That rule protects the manager from suit if at the time the manager made the decision, she believed in good faith that she was acting in the interests of her client. We believe this standard is exactly what Congress had in mind when it based Section 28(e)'s safe harbor protection on the manager's good faith determination that "the amount of commission is reasonable in relation to the value of the brokerage and research services provided." The rationale for heavy-handed record keeping and disclosure, which is weak enough when applied to private parties, loses virtually all of its force when the issue is the manager's business judgment rather than loyalty to the client.

The SEC Inspection Report fairly attempts to treat the products and services bundled together with execution by full-service brokers on an equal footing with soft dollar rebates. But the issue is how managers who use fullservice brokers can possibly meet the challenge of recording and disclosing the flow of benefits they receive. By the very nature of the relationship, these benefits are too costly to measure explicitly; they are relational in nature. Over a long course of dealing, managers might hope to assess the effect of their broker relationships on output - that is, execution quality and portfolio performance-but they cannot possibly exhaustively meter, record, and disclose the intermediate inputs. If managers were able to do so economically, they would enter into legally binding contracts with brokers for guaranteed execution quality.

The same reasoning applies to a lesser but still significant extent to soft dollar brokerage. Suppose, for example, that two brokers offer the same list of research products to a manager but that, through his own diligence and insight, one of the brokers regularly provides much more astute recommendations to the manager about which research products to use. We would naturally expect the manager to pay higher commissions to that broker, at least if the manager wants him to continue providing the service in a competitive environment. How is the manager to account for and disclose the "extra" service she gets from this broker? The Inspection Report's recommendation 
for enhanced record keeping and disclosure completely fails to recognize the nature or importance of relational trust between the manager and broker and the subtle ebbs and flows required to maintain it.

Because of electronic information processing and retrieval through the Internet and World Wide Web, we believe a strong case can be made for voluntary private certification as a substitute for mandatory detailed record keeping and disclosure. Private organizations such as the Association for Investment Management and Research and the Investment Company Institute, which rely largely on their reputations for continued support and survival, are fully capable of prescribing reasonable, workable, and informative standards of practice and disclosure for their members and their members' clients. This approach has several clear benefits. First, it allows clients who feel they can fend for themselves to do so without having to bear unnecessary costs. Second, it is voluntary and, therefore, must pass a market test. If the requirements of the private organization become either too onerous or too loose, the organization will risk losing members to rival organizations. Third, and perhaps most important, private certifying organizations will be far more agile in adjusting to the changes brought by recurrent waves of information technology. Because regulation relies on the coercive power of the state, it is hobbled by a cumbersome review-and-comment process that invariably leaves regulators one step behind the market, in spite of all good intentions and conscientious deliberations. Instead of mandatory disclosure, regulators should focus on maintaining a broad and relatively stable regulatory structure within which private parties can effectively address perceived problems. 


\section{Summary and Concluding Remarks}

Our analysis of soft dollar brokerage is surely a novel theoretical departure from the view taken by most commentators. The incentive alignment hypothesis is based on the theory that market participants will adopt the form of organization that best promotes their mutual interests, subject to the limitations imposed by agency and transaction costs. One consistent lesson from the study of economic organization is that costly wealth transfers, such as those suggested by the unjust enrichment hypothesis, reduce the size of the economic pie, so market participants can profit by organizing their activity to eliminate such transfers. As near as we can tell, plan sponsors, insurance companies, bank trusts, and other private advisory clients have not systematically entered into contracts with managers to prohibit their use of soft dollars, in spite of having the wherewithal to do so. Moreover, even where some such wealth transfers occur because of the prohibitive costs of preventing them (transaction costs), additional record keeping and disclosure imposed on private advisory clients are not likely to improve the situation at all. The SEC's Inspection Report fails to demonstrate any market failure that would justify the burden.

Some might criticize our analysis for being too theoretical and thus impractical. But to paraphrase John Maynard Keynes, those who ridicule theory as impractical are usually the mindless adherents to some outdated and confused collection of now defunct theories. Everyone deals with theories on a daily basis; they observe things in the world they do not fully understand, they formulate hypotheses to explain them, and they test their hypotheses by looking at the evidence. That is exactly what we have done here. Following the scientific method, we identified two hypotheses to explain soft dollar brokerage. Both are logically plausible. We identified situations in which these hypotheses predict different real-world outcomes. The unjust enrichment hypothesis predicts that paying up is associated with inferior portfolio performance and that it leads to lower management fees; the incentive alignment hypothesis predicts that paying up is associated with superior portfolio performance and that it has no influence on management fees. The evidence had to be inconsistent with one or the other. Our evidence refuted the unjust enrichment hypothesis while failing to refute the incentive alignment hypothesis. 
Although the scientific method does not allow us to conclude that the incentive alignment hypothesis is proven, it strongly suggests that this hypothesis is scientifically reliable (and would thus provide the foundation for admissible economic expert testimony in legal practice). The broader theories on which we relied-agency theory and the theory of economic organization-are generally accepted in the economics and finance literature; they have been scrutinized thoroughly by the profession and subjected to falsification, and they have largely avoided refutation. These criteria are exactly the ones used to assess scientific reliability as set out by the U.S. Supreme Court in the case of Daubert v. Merrell Dow Pharmaceuticals. ${ }^{24}$

Our analysis has important implications not only for legal practice but also for practicing investment managers and, indirectly, for broker/dealers. Our first suggestion is that managers formally recognize the trusting nature of their relationships with broker/dealers and the way in which soft dollar rebates (and possibly other methods of paying up) affect broker/dealers' incentives. In the absence of clear reasons to do otherwise, when negotiating soft dollar rebates, managers should take care to ensure that they receive the rebate-or have the option of receiving the rebate-before the associated trades bond the quality of the broker/dealer's executions. Managers should also consider formalizing the relationship in a letter of understanding recognizing that the broker/dealer's performance is difficult to assess and that the manager reserves the right to terminate the relationship at any time or to reduce the commission rate.

In determining the magnitude of the soft dollar account and the associated rebate, managers should accept only those research rebates whose expected value to the portfolio exceeds the value of a pure cash rebate. This approach will ensure that the manager acted in the good faith belief that, subject to the necessity of bonding the quality of the broker/dealer's executions, the manager expected to receive research products that would benefit the portfolio by more than their cost.

A letter of understanding not only formalizes the parties' expectations in a way that affirmatively protects the manager from conflict-of-interest claims; it also establishes that the manager's actual selection of research rebates is to be evaluated ex ante rather than ex post. A manager may, for example, find himself in a situation in which he has exhausted all choices of research products that benefit the portfolio more than the benefit a cash rebate would have provided but find that a cash rebate is no longer feasible. In this case, the manager will fulfill his obligation to the portfolio if he accepts products

${ }^{24} 509$ U.S. 579 (1993). For an analysis of how economic expert testimony fits into the Daubert framework, see Johnsen (1999). 
whose value to the portfolio provides the maximum possible benefit from among available alternatives. ${ }^{25}$ This standard is a clear and appropriate standard for evaluation that could easily be supported by an internal memorandum available to the client for inspection and review.

These procedures should be adequate to protect managers from conflictof-interest claims when managers accept research products that fall outside the SEC's interpretation of safe harbor research or when managers receive soft dollar rebates on principal trades. The SEC has repeatedly stated that conduct falling outside the safe harbor does not necessarily violate fiduciary principles, although it is now considering record keeping and disclosure requirements that would effectively prohibit such conduct. The incentive alignment hypothesis suggests that the standard of conduct should be based on duty of care rather than duty of loyalty and that by engaging in a modest and reasonable formalization of their expectations, the parties can comfortably engage in rebates that fall outside the safe harbor.

Finally, managers should formalize with clients their expectations regarding the use of soft dollar brokerage in a way that is consistent with the incentive alignment hypothesis. Formalization would require a letter of understanding describing the function of soft dollar brokerage in bonding broker/dealer performance and a blanket disclosure that the manager intends to accept only those research products she expects to benefit the portfolio more than a cash rebate. The letter should make clear that the manager is being called on to make a decision under uncertainty and that the propriety of the products the manager actually accepts is to be evaluated $e x$ ante rather than ex post. The letter should also describe the extent of the client's rights to insist on detailed disclosure at a later date according to an agreed standard of record keeping. This procedure should go a long way toward demonstrating that the manager acted in good faith in her brokerage allocation decisions.

\footnotetext{
${ }^{25}$ We would be interested in knowing how many cases of managers receiving inappropriate products result from the Inspection Report's reliance on an ex post evaluation rather than an ex ante evaluation.
} 


\section{Appendix A. The Mutual Fund Manager's Share}

Because assets under management are positively related to prior-period performance, paying mutual fund managers a share of assets under management gives them a stake in portfolio performance beyond the immediate compensation they receive from their advisory fees and may alleviate the agency conflicts in delegated portfolio management. Superior returns in one period attract future asset inflows on which successive management fees are earned in future periods. Over the long run, managers with superior ability should capture all excess returns as new investors contribute funds to the portfolio in anticipation of capturing subsequent excess returns. Portfolio assets will continue to grow (as will the manager's total compensation) until all excess returns are exhausted (Johnsen 1994).

In a static framework that ignores future increases (decreases) in the asset base from outperforming (underperforming) the benchmark, the dollar value of the mutual fund manager's marginal wealth at the end of one period, $M W_{m 1}$, is expressed by

$$
M W_{m 1}=\phi M W_{p 1},
$$

where $M W_{p 1}$ is the marginal wealth increase of the portfolio in Period 1 and

$$
\phi=\sum_{t=1}^{T} s(1+r)^{-t},
$$

where

$s=$ the manager's fee expressed as a percentage of assets under management

$r=$ the risk-adjusted discount rate

$T=$ the number of periods that the wealth increase persists (in an efficient market, $T$ can be presumed infinite)

But Equation A1 ignores the effect of superior performance on future inflows. Chevalier and Ellison (1997) reported that a 1 percent increase in annual portfolio return in excess of a benchmark return increases a manager's asset base the following year by about 2 percent net of investment performance. In fact, the same 1 percent excess performance increases assets two and three years in the future by about 1 percent and 0.5 percent, respectively. 
We call this measure period $t$ 's "performance elasticity of assets." Because management fees are earned on these newly attracted assets, a manager's stake in portfolio performance extends beyond the effect on current assets.

Let $\delta_{t}$ represent the percentage increase in portfolio inflows in period $t$ as a result of exceeding the return on the benchmark index by 1 percent in the first period (i.e., period $t$ 's performance elasticity of assets). If the manager outperforms the benchmark index by $n$ percent, then the manager's marginal wealth as a function of portfolio wealth increments can be written as

$$
M W_{m 1}=\phi M W_{p 1}+\frac{\phi n \delta_{1} P_{1}}{(1+r)}+\frac{\phi n \delta_{2} P_{2}}{(1+r)^{2}}+\frac{\phi n \delta_{3} P_{3}}{(1+r)^{3}}+\ldots,
$$

where $P_{t}$ is the value of the portfolio in period $t$. The first term represents the present value of the manager's benefit that is associated with portfolio wealth increases in the first period under the static view. The numerator of the second term represents the value (at the end of Period 1) of the manager's claim on $n \delta_{1} P_{1}$, the increase in portfolio assets that results from exceeding the benchmark return by $n$ percent in Period 1 . The subsequent terms are interpreted analogously for subsequent periods' asset inflows that result from superior performance in Period 1.

Making the simplifying assumption that the appropriate risk-adjusted discount rate, $r$, is equal to expected internal investment return produces

$$
M W_{m 1}=\phi M W_{p 1}+\frac{\phi n \delta_{1} P_{0}(1+r)}{(1+r)}+\frac{\phi n \delta_{2} P_{0}(1+r)^{2}}{(1+r)^{2}}+\frac{\phi n \delta_{3} P_{0}(1+r)^{3}}{(1+r)^{3}}+\ldots
$$

By dividing to unity and recognizing that $P_{0}=M W_{p 1} / r$, we can rewrite Equation A3 as

$$
\begin{aligned}
M W_{m 1} & =\phi M W_{p 1}+\frac{\phi n \delta_{1} M W_{p 1}}{r}+\frac{\phi n \delta_{2} M W_{p 1}}{r}+\frac{\phi n \delta_{3} M W_{p 1}}{r}+\ldots \\
& =\phi M W_{p 1}\left(1+\frac{n \delta_{1}}{r}+\frac{n \delta_{2}}{r}+\frac{n \delta_{3}}{r}+\ldots\right) .
\end{aligned}
$$

For example, by ignoring $\delta_{t}$ when $t>3$, the manager's wealth increment can be estimated by using asset elasticity estimates from Chevalier and Ellison, where $\delta_{1}=0.02, \delta_{2}=0.01, \delta_{3}=0.005$. Assuming wealth increases are permanent, $s=0.01, r=10$ percent, and the portfolio return exceeds the benchmark index by 1 percent, then the manager's marginal benefit from each marginal dollar of portfolio wealth is

$$
M W_{m 1}=0.10(\$ 1.00)\left(1+\frac{0.02}{0.10}+\frac{0.01}{0.10}+\frac{0.005}{0.10}\right)=0.135 \text {. }
$$


That is, for each incremental dollar of portfolio wealth, the manager gains 13.5 cents, which corresponds to the manager's share, $f$, in Figures 1-3. When the manager outperforms the index by 2 percent,

$$
M W_{m 1}=0.10(\$ 1.00)\left(1+\frac{2(0.02)}{0.10}+\frac{2(0.01)}{0.10}+\frac{2(0.005)}{0.10}\right)=0.17 .
$$

An examination of this example and the positive first derivative with respect to $n$ of Equation A4 reveals that managers receive increasing marginal wealth as portfolio returns increase. Unlike some commentators, we find it difficult to believe that institutional money management is an industry that subtracts value when managers are given such a large stake in their marginal performance, substantially sharing ownership in the portfolioespecially when much of the manager's payment comes in the form of future performance-induced fund flows based on investors' (presumably rational) expectations. When compared with corporate managers' average inside ownership, this stake is large. 


\section{References}

AIMR Soft Dollar Standards. 1998. Charlottesville, VA: Association for Investment Management and Research.

Ambachtsheer, Keith P. 1994. "The Economics of Pension Fund Management." Financial Analysts Journal, vol. 50, no. 6 (November/December):21-31.

Berkowitz, Stephen A., Dennis E. Logue, and Eugene A Noser, Jr. 1988. "The Total Cost of Transactions on the NYSE." Journal of Finance, vol. 43, no. 1 (February):97-112.

Burgunder, Lee B., and Carl O. Hartmann. 1986. "Soft Dollars and Section 28(e) of the Securities Exchange Act of 1934: A 1985 Perspective." American Business Law Journal, vol. 24:139-177.

Chan, Louis K.C., and Josef Lakonishok. 1993. "Institutional Trades and Intraday Stock Price Behavior." Journal of Financial Economics, vol. 33, no. 2 (April):173-199.

Chevalier, Judith, and Glen Ellison. 1997. "Risk Taking by Mutual Funds as a Response to Incentives." Journal of Political Economy, vol. 105, no. 6:1167-1200.

Coase, Ronald H. 1979. "Payola in Radio and Television Broadcasting." Journal of Law \& Economics, vol. 22, no. 2 (October):269-328.

Donnelly, Barbara. 1991. “Street Squabble: Who Controls Research?” Wall Street Journal (June 11):C1.

Fama, Eugene, and Kenneth French. 1993. "Common Risk Factors in the Returns of Stocks and Bonds.” Journal of Financial Economics, vol. 33, no. 1 (February):3-56.

Grinblatt, Mark, and Sheridan Titman. 1989. "Mutual Fund Performance: An Analysis of Quarterly Portfolio Holdings." Journal of Business, vol. 62, no. 3:393-416.

Gruber, Martin J. 1996. "Another Puzzle: The Growth in Actively Managed Mutual Funds.” Journal of Finance, vol. 51, no. 3 (July):783-810. 
Inspection Report on the Soft Dollar Practices of Broker/Dealers, Investment Advisers and Mutual Portfolios. 1998. Washington, DC: U.S. Securities and Exchange Commission, Office of Compliance, Inspections and Examinations (September 22).

Ippolito, Richard A. 1989. "Efficiency with Costly Information: A Study of Mutual Portfolio Performance: 1965-1984.” Quarterly Journal of Economics, vol. 104, no. 1 (February):1-23.

Jarrell, Gregg A. 1984. "Change at the Exchange: The Causes and Effects of Deregulation." Journal of Law \& Economics, vol. 27, no. 2 (October):273-312.

Jensen, Michael C. 1968. "The Performance of Mutual Funds in the Period 1945-1964.” Journal of Finance, vol. 23, no. 2 (April):389-416.

Jensen, Michael C., and William H. Meckling. 1976. "Theory of the Firm: Managerial Behavior, Agency Costs and Ownership Structure.” Journal of Financial Economics, vol. 3, no. 4:305-360.

Johnsen, D. Bruce. 1994. "Property Rights to Investment Research: The Agency Costs of Soft Dollar Brokerage.” Yale Journal on Regulation, vol. 11, no. 1 (Winter):75-113.

1999. "Daubert, the Scientific Method, and Economic Expert Testimony.” Kansas Journal of Law and Public Policy, vol. 9, no. 1 (Fall):149-164.

Keim, Donald B., and Ananth Madhavan. 1995. "Anatomy of the Trading Process: Evidence on the Behavior of Institutional Traders." Journal of Financial Economics, vol. 37, no. 3 (December):371-398.

Klein, Benjamin, and Keith B. Leffler. 1981. "The Role of Market Forces in Assuring Contractual Performance.” Journal of Political Economy, vol. 81, no. 4 (August):615-641.

Lehman, Bruce N., and David M. Modest. 1987. "Mutual Fund Performance Evaluation: A Comparison of Benchmarks and Benchmark Comparisons.” Journal of Finance, vol. 42, no. 2 (April):233-265.

Logue, Dennis E. 1991. Managing Corporate Pension Plans. New York: Harper Business.

Maher, Philip. 1989. "Why Wall Street Can’t Bank on Soft Dollars.” Investment Dealers’ Digest (October 23):18-21.

Malkiel, Burton G. 1995. "Returns from Investing in Equity Mutual Funds 1971 to 1991." Journal of Finance, vol. 50, no. 2 (June):549-572. 
Pozen, Robert C. 1976. "Money Managers and Securities Research." N.Y.U. Law Review, vol. 51, no. 6 (December):923-980.

Roll, Richard. 1978. "Ambiguity When Performance Is Measured by the Securities Market Line.” Journal of Finance, vol. 33, no. 4 (August):1051-69.

Schneeweis, Thomas, and Richard Spurgin. 1998. "Multifactor Analysis of Hedge Fund, Managed Futures, and Mutual Fund Return and Risk Characteristics." Journal of Alternative Investments, vol. 1, no. 2:1-24.

Schramm, Sabine. 1994. "Indexing Shows Small Increase: International Posts the Only Big Gains." Pensions \& Investments, vol. 22, no. 3 (February):2-4.

Schwartz, Robert, and James Shapiro. 1992. "The Challenge of Institutionalization for the Equity Markets." In Recent Developments in Finance. Edited by Anthony Saunders. New York: New York University Salomon Center.

Shapiro, S.S., and M.B. Wilk. 1965. "An Analysis of Variance Test for Normality.” Biometrika, vol. 52:591-611.

Taylor, Jeffrey. 1995. "SEC Wants Investment Managers to Tell Clients More about Soft Dollar Services.” Wall Street Journal (February 15):A6. 